\title{
Progressividade e Aspectos Distributivos na Previdência Social: Uma Análise com o Emprego dos Microdados dos Registros Administrativos do RGPS
}

\author{
Luís Eduardo Afonso ${ }^{\dagger}$
}

Sumário: 1. Introdução; 2. Fundamentos teóricos e evidências empíricas; 3. Dados e Metodologia; 4. Resultados; 5. Conclusões.

Palavras-chave: Previdência Social, Aspectos Distributivos, Progressividade, RGPS, Registros Administrativos.

Códigos JEL: H55, J14.

\begin{abstract}
Este trabalho quantifica os aspectos distributivos das Aposentadorias por Tempo de Contribuição e Aposentadorias por Idade do INSS, com os microdados dos registros administrativos do RGPS. A Taxa de Reposição média foi 82,52\%, a Taxa Interna de Retorno média foi 5,32\% e o valor médio da Alíquota Necessária foi de 50,53\%. Propõe-se também um novo indicador, a Contribuição Adicional e o cálculo da Alíquota Necessária com o emprego da Taxa Interna de Retorno individual. Foram encontradas fortes evidências de progressividade. Valores maiores para todos indicadores foram obtidos para mulheres, indivíduos menos escolarizados, de menor renda e para aposentadorias por idade.
\end{abstract}

This paper quantifies the distributional aspects and progressivity of the benefits of Length of Contribution Retirement and Age Retirement of INSS, with microdata from administrative records of RGPS. Average Replacement Rate is $82,52 \%$, average Internal Rate of Return is 5,32\% and average Necessary Tax Rate is 50,53\%. We also propose a new indicator, the Additional Contribution and calculate the Necessary Tax Rate using the individual Internal Rate of Return. Strong evidence of progressivity was found. Higher values for all indicators were obtained for women, less educated individuals and poorer individuals and for the Age Retirement benefit.

\footnotetext{
*Este artigo é originado da tese de livre-docência do autor, que agradece o financiamento do CNPq, por meio do Edital MCT/CNPq $\mathrm{N}^{\circ}$ 014/2010-Universal. Foi fundamental o apoio de Rogerio Nagamine Costanzi para a obtenção dos microdados dos registros administrativos do Ministério do Trabalho e Previdência Social. O autor é grato a Cassio Maldonado Turra, Georges Langis, Giselle Datz, João Vinícius de França Carvalho e Samuel de Abreu Pessôa pelos comentários e sugestões feitos a versões anteriores deste trabalho. Finalmente, é importante agradecer o trabalho do assistente de pesquisa Luiz Henrique Cruz e Superti.

${ }^{\dagger}$ Departamento de Contabilidade e Atuária da FEA/USP. Av. Prof. Luciano Gualberto 908, prédio FEA-3, sala 215. Cidade Universitária, Butantã, São Paulo-SP. CEP 05508-010. E-mail: lafonso@usp.br
} 


\section{INTRODUÇÃO}

Este trabalho visa quantificar os aspectos distributivos e a progressividade dos beneficios de Aposentadoria por Tempo de Contribuição (ATC) e Aposentadoria por Idade (AI) do Regime Geral de Previdência Social (RGPS) do Instituto Nacional do Seguro Social (INSS). Isto é feito por meio do cálculo de Indicadores Previdenciários. São empregados os microdados dos registros administrativos do Ministério da Previdência Social (MPS). Fazem parte do banco de dados 35.000 indivíduos nascidos em 1930, 1935, 1940, 1945, 1950, 1955 e 1960. A hipótese inicial é a existência de progressividade no RGPS. Ou seja, os ganhos oriundos da participação no sistema previdenciário são mais elevados para beneficiários de renda mais baixa, para mulheres e para indivíduos que se aposentam por idade. Inspirado em Pallares-Miralles, Romero \& Whitehouse (2012), definem-se os Indicadores Previdenciários como a medida operacional da performance de um sistema previdenciário. Em particular, o foco é a capacidade de a previdência repor renda, reduzir a pobreza e financiar de forma adequada os beneficios.

A relevância do tema fundamenta-se em dois argumentos. O primeiro, de caráter macroeconômico, é o tamanho do dispêndio previdenciário. Em 2014 as despesas com pagamentos de benefícios do RGPS foram de $7,9 \%$ do PIB brasileiro, com déficit associado próximo a 1,7\% do PIB. 0 segundo argumento, de natureza microeconômica, é que sistemas previdenciários promovem a realocação intertemporal de recursos dos indivíduos. Este fato pode gerar impactos significativos sobre a distribuição de recursos na economia, tanto de forma intergeracional, quanto de forma intrageracional. Esta realocação pode ocorrer de forma diferenciada para os contribuintes e beneficiários, de acordo com características como coorte, sexo, tipo de benefício, escolaridade (de forma indireta) e nível de renda. Esta redistribuição por vezes pode ser intencional ou não (Gragnolati, Jorgensen, Rocha \& Fruttero, 2011), o que é uma evidência da importância de sua quantificação na agenda de estudos sobre temas previdenciários.

Embora a literatura nacional tenha produzido contribuições importantes (Giambiagi \& Afonso, 2009; Moura, Jesus Filho, Tafner \& Ourives, 2013, dentre outros) existe uma lacuna comparativamente aos trabalhos internacionais no tocante às bases de dados. Grosso modo, os trabalhos sobre previdência podem ser divididos em quatro grupos. No primeiro são empregados indivíduos representativos, construídos com base em determinadas características observáveis, nos termos de Leimer (1999). O segundo grupo utiliza microdados em cross-section, oriundos dos Censos ou de pesquisas domiciliares amostrais, como a Pesquisa Mensal de Emprego (PME) e a Pesquisa Nacional por Amostra de Domicílios (PNAD). Seu uso apresenta uma restrição: as informações de um determinado momento podem não representar bem a evolução das variáveis de interesse. O terceiro grupo utiliza microdados em painel. Acompanhase o mesmo conjunto de pessoas por vários anos. O quarto grupo emprega microdados dos registros administrativos das instituições previdenciárias. São informações de fato verificadas de contribuintes e beneficiários, por longos períodos. Como são oriundas de indivíduos reais, têm a vantagem de retratar com maior acurácia os sistemas previdenciários.

A literatura sobre aspectos distributivos tem convergido para o emprego de microdados dos registros administrativos. Podem ser citados vários trabalhos nessa linha. Por exemplo, Bertranou \& Sánchez (2003), Bucheli, Forteza \& Rossi (2010), Reznik, Weaver \& Biggs (2009), Shoven \& Slavov (2012a), Shoven \& Slavov (2012b), e Schröder (2012). No caso brasileiro, a lacuna é o não emprego de registros administrativos, o que limita métodos, força a adoção de premissas e hipóteses por vezes heroicas e limita sobremaneira a generalização das conclusões. As consequências são a reduzida comparabilidade com os trabalhos internacionais e sua menor utilidade como subsídio aos formuladores de políticas públicas.

Uma vez descrito este quadro, considera-se que este trabalho tem a possibilidade de fazer uma contribuição original, por três motivos. O primeiro é o cálculo dos Indicadores Previdenciários, de forma similar ao verificado em trabalhos empíricos, com o intuito de analisar a progressividade dos sistemas previdenciários, como Alonso, Hoyo \& Tuesta (2015) e Shoven \& Slavov (2014). O segundo é o emprego de registros administrativos do RGPS, em consonância com o estado das artes da literatura. Até onde se tem conhecimento, esta é a primeira vez que os microdados do RGPS são usados com esta finalidade. Finalmente, o terceiro é a proposição de algumas modificações na forma de cálculo e interpretação de 
alguns dos Indicadores.

Este trabalho tem mais quatro seções, além desta breve introdução. Na seção 2 são apresentados os aspectos mais teóricos mais relevantes da literatura sobre previdência social, com ênfase nos aspectos distributivos. Na sequência faz-se a exposição dos Indicadores Previdenciários e dos principais resultados da literatura empírica relevante. Na seção 3 explica-se a metodologia empregada na construção do banco de dados, tendo como base os registros administrativos do RGPS. A seção 4 traz os resultados do cálculo dos Indicadores Previdenciários. Finalmente, apresentam-se as conclusões da tese.

\section{FUNDAMENTOS TEÓRICOS E EVIDÊNCIAS EMPÍRICAS}

\subsection{Fundamentos e critérios de avaliação de sistemas previdenciários}

\subsubsection{Fundamentos teóricos}

Um sistema previdenciário tem como função básica o pagamento de benefícios de forma continuada às pessoas que deixam o mercado de trabalho, como forma de repor seu padrão de consumo, ainda que de forma parcial, quando de sua aposentadoria. Usualmente o recebimento dos benefícios está condicionado ao pagamento anterior de contribuições previdenciárias, incidentes sobre a renda dos trabalhadores. O RGPS funciona sob o regime de repartição. Não há acumulação de recursos. As aposentadorias têm seu valor calculado com base em regras do tipo benefício definido. Ou seja, é conhecida a fórmula de cálculo do benefício e, principalmente, como esta está atrelada ex-ante a um determinado conjunto de condições. Tendo em vista as características apresentadas e a classificação do RGPS, a partir deste ponto toda a análise terá como foco única e exclusivamente os regimes de repartição com benefício definido.

Desde o clássico trabalho de Samuelson (1958), retomado por Aaron (1966), sabe-se que um regime de repartição pode aumentar o bem-estar de cada indivíduo na sociedade. Isto acontecerá se a taxa de crescimento das contribuições (dada pelas taxas de crescimento da renda e da população ativa) superar a taxa de juros da economia. No entanto, esta conclusão, embora fundamental e basilar para parcela expressiva da literatura, não dá conta de várias características importantes dos sistemas previdenciários. Um exemplo são os aspectos distributivos e a progressividade.

A redistribuição feita por um sistema previdenciário pode ser classificada em duas categorias. A primeira é a distribuição intergeracional, ou seja, entre gerações ou coortes diferentes. Este processo é inerente à lógica de um regime PAYG, tendo em vista o financiamento dos benefícios de cada geração pela geração seguinte. Cada coorte pode ser impactada de forma distinta pelo sistema previdenciário. A segunda categoria é a distribuição intrageracional. É oriunda da heterogeneidade que existe entre indivíduos de uma mesma coorte, podendo também ser gerada ou acentuada pelo tratamento desigual que o sistema previdenciário dá a trabalhadores da mesma geração. Com base nestas características, define-se que o termo aspectos distributivos está ligado à mensuração tanto da distribuição intergeracional, quanto da distribuição intrageracional. O termo progressividade é empregado no contexto usual da literatura sobre finanças públicas, conforme discutido, por exemplo, por Musgrave (1985). É de se esperar que a redistribuição gerada pela previdência seja progressiva (Brown \& Ip, 2000, p.3).

\subsubsection{Critérios de avaliação de sistemas previdenciários}

Conforme apontam Brown \& Ip (2000), aspectos ligados à adequação, equidade e progressividade são relevantes para a avaliação de sistemas de previdência. Barr \& Diamond $(2006,2008,2009)$ apontam que um sistema previdenciário deve ter o objetivo de proporcionar segurança econômica na velhice, por meio da suavização do consumo, mitigação da pobreza e redistribuição. 0 design de um sistema previdenciário deve procurar maximizar essa segurança na velhice, o que inclui o custo de provisão do bem (a previdência social). Estas proposições trazem implícitos alguns critérios de avaliação:

Adequação: capacidade de o sistema repor renda e proporcionar uma forma de seguro contra situações econômicas adversas; 
Universalização: proporção de idosos atendida pelo sistema;

Custo de provisão: entendido de forma intertemporal, com base na evolução das variáveis econômicodemográficas que afetam o equilíbrio dos regimes de repartição;

Eficiência ou equidade individual: maior linkage entre contribuições e benefícios;

\section{Incentivo ao crescimento econômico.}

Há consenso sobre os pontos mais relevantes do desenho dos sistemas previdenciários. Entretanto, também ficam evidentes as dificuldades operacionais para se encontrar métricas adequadas e, principalmente, dados de boa qualidade, que permitam a mensuração destes pontos. Portanto, com base na discussão apresentada, optou-se por uma escolha que privilegie dois aspectos. 0 primeiro é a adequação; o segundo é a equidade individual. Esta é uma maneira de analisar e quantificar os aspectos distributivos intrageracionais e intergeracionais, ou seja, verificar a progressividade do RGPS.

\subsection{Indicadores Previdenciários}

O primeiro indicador é a Taxa de Reposição (TR). Corresponde à razão entre o primeiro benefício previdenciário $B_{i t}$, recebido pelo indivíduo $i$ no instante $t$ e a última remuneração anterior à aposentadoria $W_{i t-1}$. Seu cálculo é dado na equação (1). Quando são empregados os valores brutos, este conceito é denominado TR bruta. Para o cálculo da TR líquida, devem ser usados os valores após a incidência dos tributos. Adotou-se a TR bruta, por quatro motivos. O primeiro é a consistência com relação aos critérios adotados pelo IBGE em suas pesquisas. $O$ segundo é que todos os dados da base original são brutos. $O$ terceiro motivo é que é mais adequado o uso da TR bruta, tendo em vista que o objetivo é analisar características do RGPS. Caso valores líquidos fossem usados, características do sistema tributário afetariam os resultados. $\mathrm{O}$ quarto motivo é que a TR bruta é a forma mais adotada na literatura.

$$
\mathrm{TR}_{i}=\frac{B_{i t}}{W_{i t-1}} .
$$

A primeira vantagem da TR é a simplicidade. É possível calcular a TR com duas observações de duas variáveis, em períodos consecutivos. Sendo um indicador "quase contemporâneo", a correção de valores nominais é virtualmente irrelevante. A segunda é a comparabilidade: medidas da TR são comparáveis para benefício de sistemas previdenciários de países distintos. A terceira vantagem é que o cálculo da TR prescinde da escolha da taxa de desconto. $O$ último ponto é a compreensibilidade. Por ser uma medida relativa de poder de compra real, pode ser compreendida até mesmo por leigos.

Os motivos que fazem com que a TR seja tão utilizada, também a fazem incompleta. Como lembram Biggs, Sarney \& Tamborini (2009), a TR não permite nenhuma conclusão sobre aspectos lifetime, inerentes à lógica dos sistemas previdenciários. Este fato justifica o cálculo de outros indicadores. 0 segundo indicador é a Taxa Interna de Retorno (TIR), apresentada na equação (2). 0 termo do lado esquerdo é o valor presente das contribuições $C_{i t}$ descontadas à taxa TIR, denominado VPC. A somatória tem início quando da primeira contribuição. $O$ termo $N$ corresponde ao último período contributivo. Para os beneficios $B_{i t}$, a explicação é similar. A somatória inicia-se em $N+1$, em que ocorre o recebimento do primeiro benefício, prolongando-se até a idade terminal $\omega$. Este somatório é o Valor Presente dos Benefícios (VPB). A TIR, por definição, é a taxa que iguala os fluxos dos dois lados da expressão.

$$
\mathrm{VPC}_{i}=\sum_{t=1}^{N} \frac{C_{i t}}{(1+\mathrm{TIR})^{t}}=\sum_{t=N+1}^{\omega} \frac{B_{i t}}{(1+\mathrm{TIR})^{t}}=\mathrm{VPB}_{i} .
$$

A Taxa Interna de Retorno tem características que explicam seu uso tão difundido. A primeira delas é que, assim como a TR, é uma variável que não é expressa em unidades monetárias, o que favorece a compreensão e a comparabilidade entre sistemas diferentes. A segunda, e talvez mais importante, é que 
TIR é calculada endogenamente, por meio da equação (2). Desta maneira em seu cálculo não é necessária a escolha de uma taxa de desconto, tendo em vista que esta é exatamente a definição daTIR.

Finalmente, o terceiro indicador é a Alíquota de Contribuição Necessária (AliqNec), apresentado na equação (3). Este é um conceito de cunho atuarial, pois representa qual deveria ser a alíquota de contribuição incidente sobre a renda, de tal forma que o valor presente esperado dos benefícios VPB seja igual ao valor presente esperado da renda VPR. Isto pode ser notado pela multiplicação do denominador da equação (3) por AliqNec, o que gera o valor presente das contribuições VPC.

$$
\operatorname{AliqNec}_{i}=\frac{\sum_{t=N+1}^{\omega} \frac{B_{i t}}{(1+r)^{t}}}{\sum_{t=1}^{N} \frac{R_{i t}}{(1+r)^{t}}}=\frac{\mathrm{VPB}}{\mathrm{VPR}} .
$$

Dentre todos os indicadores, este merece mais de atenção, devido à discricionariedade, quanto à taxa de desconto $r$. Quando este cálculo é feito para regimes fundados, em que há acumulação de ativos, a escolha da taxa $r$ é consensual. Sua escolha deve refletir as características dos ativos que irão garantir os benefícios previdenciários. No entanto, para regimes de repartição, tal escolha não é tão óbvia. Uma possível explicação é que o conceito de ativo em um regime de repartição é bem menos claro do que em um regime de capitalização. Neste último, a existência de mercados para os ativos, permite que estes sejam transacionados por ofertantes e demandantes, definindo de maneira mais adequada o seu preço. Já em um regime de repartição, pode ser entendido que o ativo que lastreia os benefícios, denominado Contribution asset por Boado-Penas, Valdés-Prieto \& Vidal-Meliá (2008) são as contribuições dos trabalhadores ativo, que geram os recursos para pagamento dos benefícios previdenciários a cada instante do tempo.

\subsection{Evidências empíricas}

Segundo Aldrich (1982), o trabalho pioneiro no emprego da TR foi feito por Horlick (1970). O autor comparou trabalhadores representativos do setor de manufatura de 13 países. 0 valor médio para a TR está na faixa dos 40\%. Este trabalho foi atualizado por Haanes-Olsen (1978), utilizando dados dos mesmos países. $O$ autor encontra resultados mais elevados para a TR, sendo o valor mais baixo de $26 \%$ (Reino Unido) e o mais alto de 67\% (Suécia). Aldrich (1982) voltou ao tema, analisando os mesmos 12 países, porém com dados do período 1969-1980. Seus resultados reforçam os achados de Haanes-Olsen (1978), que havia encontrado tendência de crescimento da TR, comparativamente a Horlick (1970).

Duas importantes análises para o caso norte-americano são feitas por Leimer $(2004,2007)$. No primeiro trabalho o autor estuda os aspectos distributivos do OASI para as coortes nascidas até 1922, com o emprego de microdados dos registros administrativos. 0 autor encontra evidências da existência de um windfall ${ }^{1}$ para as gerações iniciais. No trabalho de 2007, estas estimativas são atualizadas, incorporando novas premissas demográficas e de evolução do Trust Fund. Ratificou-se o resultado de queda da TIR, cujo valor passa de $18,4 \%$ para a coorte nascida até 1900 , até atingir $2,7 \%$ para a coorte nascida em 1945.

Este padrão de resultados é semelhante ao que havia sido reportado por Hurd \& Shoven (1985). Neste caso, o objetivo principal é verificar como o início do sistema previdenciário nos EUA afetou a coorte nascida entre 1905 e 1911. Para indivíduos casados, as TIRs reportadas são da ordem de 8,4\%, enquanto Leimer (2007) encontra TIRs próximas as 8,6\%. Duggan, Gillingham \& Greenlees (1993) reforçam os resultados pró-progressividade do OASDI. São analisados os indivíduos de quatro coortes: 1895-1903,

\footnotetext{
${ }^{1}$ Um regime de repartição baseia-se em transferências das gerações mais novas para as mais antigas. Quando um sistema previdenciário começa, a primeira geração pode receber benefícios, sem que tenha realizado as contribuições necessárias (Feldstein \& Liebman, 2002).
} 
1904-1910, 1911-1916 e 1917-1922. A TIR média reportada é de 9,1\%. As TRs das mulheres são superiores em 2,5\% às TRs masculinas. 0 mesmo ocorre para os não-brancos e para os trabalhadores de renda mais baixa. Finalmente, são encontradas evidências de windfall para as gerações mais antigas.

Um importante avanço nesta literatura ocorre no meio da década de 90 quando Garrett (1995) incorpora a mortalidade diferenciada por faixa de renda. Neste caso, a clara evidência de progressividade no OASDI (por meio de TIRs mais elevadas para os indivíduos de renda mais baixa) é questionada, tendo em vista que as maiores TIRs são obtidas por trabalhadores das faixas intermediárias de renda. No mesmo ano, Duggan, Gillingham \& Greenlees (1995) também obtêm resultados menos conclusivos ao empregar taxas de mortalidade por nível de renda. Brown (1998) também incorpora os diferenciais de mortalidade por renda, ao analisar o OASDI e o Canada/Quebec Pension Plans (C/QPP). O autor conclui que ambos os sistemas apresentam progressividade, sendo esta conclusão mais forte para o OASDI.

Uma série importante de contribuições para os países da América Latina é feita por Forteza \& Ourens $(2009,2012)$ e Forteza et al. (2009). No primeiro trabalho são calculadas as TIRs e TRs de 11 países. Os autores encontram progressividade, pois as TIRs são mais elevadas para os contribuintes de renda mais baixa. Obviamente esta conclusão não é válida para os países que têm regimes de capitalização, como Chile, Uruguai e Colômbia. Também de forma genérica, as TRs calculadas são bastante elevadas, atingindo em mais da metade dos países valores superiores a $100 \%$.

Em Forteza et al. (2009) há uma modificação metodológica: os autores empregam registros administrativos dos regimes previdenciários do Chile e do Uruguai. Para o Chile encontram-se TRs muito reduzidas: cerca de $35 \%$ para homens e $11 \%$ para as mulheres. Quando se incorporam as mudanças legais introduzidas em 2008 , os valores aumentam para cerca de $50 \%$ e $28 \%$, respectivamente. Forteza \& Ourens (2012) voltam a analisar os 11 países do trabalho de 2009, novamente empregando indivíduos representativos, porém desta vez com um modelo de simulação. Mantém-se a conclusão de progressividade, visto que as TIRs são mais elevadas para os indivíduos de renda mais baixa.

No Brasil talvez o primeiro trabalho a tratar deste tema tenha sido Fernandes (1994). Este autor pesquisou a heterogeneidade intergeracional, analisando diversas coortes, a partir de 1930-1935. Por hipótese, no modelo estilizado de previdência utilizado, todos se aposentam aos 60 ou aos 65 anos. Neste segundo caso, a TIR masculina da primeira coorte seria de 1,98\%. Para a coorte de 1985-1990, foi encontrada uma taxa negativa: $-0,01 \%$. Para as mulheres, os valores seriam de $2,83 \%$ e $0,67 \%$, respectivamente. Estes valores enfatizam a hipótese do windfall e de progressividade.

Afonso \& Fernandes (2005) calculam as TIRs para as coortes nascidas a partir de 1920, com desagregação por nível de educação e região do país, empregando os microdados das PNADs de 1976 a 1999. A TIR média encontrada é de $6,7 \%$. Há evidências de progressividade, pois os valores médios da região nordeste são mais de 1,5 ponto percentual acima das demais regiões. Analogamente, indivíduos com menor nível educacional têm TIR mais de um ponto percentual acima da média. Conclusão similar no tocante às transferências de renda foi obtida por Reis \& Turra (2011), que incorporaram as diferenças de composição da população e os diferenciais de mortalidade entre regiões.

Giambiagi \& Afonso (2009) concentram seu foco nas ATCs do RGPS, fazendo uso dos microdados da PNAD 2007. Os autores encontram evidências de progressividade: as alíquotas necessárias das mulheres são mais elevadas frente aos homens. Para quase todos os casos analisados os valores são inferiores às alíquotas efetivas (evidência da existência de subsídios cruzados entre os benefícios do RGPS). Quando as TRs são analisadas, o padrão de resultados é um pouco menos claro: os valores obtidos pelos grupos com maior escolaridade são cerca de 12 pontos inferiores em relação aos grupos de menor escolaridade. Conclusões similares foram obtidas também por Penafieri \& Afonso (2013).

Os possíveis subsídios cruzados existentes no RGPS são o foco de Caetano (2006). 0 autor calcula as TIRs de vários grupos de contribuintes, separados por gênero, Espécie de benefício e incidência do fator previdenciário. Para um homem que entrou no mercado de trabalho aos 18 anos e se aposentou por tempo de contribuição aos 53 anos, a TIR é de 1,68\%. Para uma mulher que tenha se aposentado após 30 anos de contribuição, a TIR é de 2,51\%. Encontram-se evidências de progressividade, sendo que as TIRs mais baixas são encontradas para as ATCs masculinas em que há incidência do fator e as TIRs 
mais elevadas são obtidas para as mulheres que se aposentam por idade, recebendo um salário mínimo.

Com base nestes trabalhos é possível chegar a quatro conclusões. É consensual que os sistemas previdenciários têm caráter progressivo. A segunda conclusão é que há fortes evidências de existência de windfall, com ganhos para as primeiras gerações com acesso ao sistema previdenciário. A terceira conclusão é que os ganhos são diferentes e decrescentes ao longo do tempo. Por último, verifica-se a existência de transferências intrageracionais, entre indivíduos de uma mesma coorte.

\section{DADOS E METODOLOGIA}

\subsection{Construção do banco inicial a partir dos registros administrativos do RGPS}

Os registros são oriundos das bases de dados da Empresa de Tecnologia e Informações da Previdência Social (Dataprev). Os microdados têm periodicidade mensal, compreendendo o período de 27 anos, de janeiro de 1980 a dezembro de 2006 . Originalmente foram recebidos dois conjuntos de dados. 0 primeiro é o Arquivo de Cadastro e Vínculos e Remunerações. O segundo conjunto de dados é denominado Arquivo de Benefícios, com as informações posteriores ao início do recebimento do benefício previdenciário.

\subsubsection{Vínculos e Remunerações}

Neste banco há um identificador único para cada indivíduo. A codificação da escolaridade é apresentada na Tabela 1. A variável Pensão informa se o benefício é uma pensão ou não. A variável Competência Vínculo é uma dummy que informa se no mês em questão há registro de remuneração (e contribuição) ao RGPS. A variável tem valor 1 em caso positivo e 0 , em caso contrário. Há 324 ocorrências, pois este é o resultado da multiplicação dos 12 meses do ano pelos 27 anos da amostra. Finalmente, a variável Remuneração-Vínculo traz o valor da remuneração do segurado, em múltiplos do salário mínimo (SM) nominal vigente na época, multiplicado por 100.

Inicialmente há 5.000 indivíduos de cada coorte, com nascidos nos anos de 1930, 1935, 1940, 1945, 1950, 1955 e 1960, em um total de 34.998 segurados. $^{2}$ Há ligeira predominância masculina $(53,2 \%)$ na amostra. Como o número de categorias é muito elevado e o número de contribuintes por categoria é muito pequeno (considerando os mais de $60 \%$ que compõem a categoria 0 ), decidiu-se fazer uma agregação em quatro Grupos Educacionais, da maneira descrita na Tabela 2. Portanto, todos os resultados serão expressos com o emprego destes quatro grupos.

Tabela 1. Distribuição da escolaridade por categoria.

\begin{tabular}{clrr}
\hline Categoria & Descrição & Número & \multicolumn{1}{c}{$\%$} \\
\hline 0 & Sem informação & 21.425 & 61,22 \\
1 & Analfabeto & 1.831 & 5,23 \\
2 & ${\text { Até a 4a série incompleta do } 1^{\circ} \text { Grau (primário incompleto) }}^{\text {a }}$ & 3.438 & 9,82 \\
3 & $4^{\mathrm{a}}$ série completa do $1^{\circ}$ Grau (primário completo) & 2.752 & 7,86 \\
4 & $5^{\mathrm{a}}$ à $8^{\mathrm{a}}$ série incompleta do $1^{\circ}$ Grau (ginásio incompleto) & 1.359 & 3,88 \\
5 & $1^{\circ}$ grau (ginásio) completo & 1.214 & 3,47 \\
6 & $2^{\circ}$ grau (colegial) incompleto & 418 & 1,19 \\
7 & $2^{\circ}$ grau (colegial) completo & 1.399 & 4,00 \\
8 & Superior incompleto & 219 & 0,63 \\
9 & Superior completo & 943 & 2,69 \\
\hline Total & & 34.998 & 100,00 \\
\hline
\end{tabular}

Fonte: Tabulações do autor, com base nos registros administrativos da Dataprev.

${ }^{2}$ Um problema com dois registros da coorte de $1930 \mathrm{fez} \mathrm{com} \mathrm{que} \mathrm{o} \mathrm{banco} \mathrm{tivesse} \mathrm{na} \mathrm{verdade} 34.998$ indivíduos. 
Tabela 2. Grupos educacionais.

\begin{tabular}{cc}
\hline Grupo Educacional & Escolaridade (categoria) \\
\hline 0 & 0 \\
1 & $1,2,3$ e 4 \\
2 & 5,6 e 7 \\
3 & 8 e 9 \\
\hline
\end{tabular}

\subsubsection{Beneficios}

Os bancos do Arquivo de Benefícios têm estrutura similar aos bancos do Arquivo de Cadastro e Vínculos e Remunerações. Há informações sobre a Espécie de benefício, conforme a classificação dos Benefícios de Prestação Continuada do MPS, a data de início do benefício (DIB), a data de cessação do benefício (DCB) e se o benefício é uma Pensão. A variável RMI expressa o valor do primeiro pagamento do benefício, expresso em múltiplos do salário mínimo nominal vigente. Porém, de forma distinta do que ocorre para as remunerações, no banco de Benefícios consta apenas o valor do primeiro benefício pago. Por meio do identificador único os componentes deste banco são identificados e atribuídos aos registros do Cadastro de Vínculos e Remunerações. No caso dos benefícios só há registros para indivíduos que no período analisado (1980 a 2006) já tinham a condição de beneficiários. Por este motivo, o tamanho destes bancos é menor do que os bancos de vínculos e remunerações, conforme pode ser visto na Tabela 3. Há 34.998 registros no banco de remunerações, mas no banco de benefícios há apenas 22.916 indivíduos. $\mathrm{E}$ deste total, somente 5.270 são aposentadorias por idade e 2.107 são ATCs.

A etapa seguinte consiste na construção de um banco único para contribuições e benefícios para os indivíduos de todas as coortes. Foram mantidas no banco apenas duas espécies de benefícios: Aposentadoria por Tempo de Contribuição (ATC) - Código 42 - e Aposentadoria por Idade (AI) - Código 41. Dois motivos justificam esta escolha. O primeiro é que, dentre todo o rol de benefícios pagos pelo INSS, estas são as espécies que mais claramente podem ser classificadas como previdenciárias. Ou seja, por natureza são benefícios com características programáveis para os quais é razoável pensar na relação entre benefícios e contribuições. O segundo motivo é que a literatura internacional trata basicamente dos benefícios programáveis. Optou-se por excluir do banco de dados todas as pensões. A razão principal é a impossibilidade de identificação destas pensões com base no benefício que lhes deu origem.

Tabela 3. Distribuição dos beneficiários por ano de nascimento.

\begin{tabular}{crr}
\hline Ano de nascimento & Número & \multicolumn{1}{c}{$\%$} \\
\hline 1930 & 3.319 & 14,48 \\
1935 & 4.037 & 17,62 \\
1940 & 3.990 & 17,41 \\
1945 & 3.928 & 17,14 \\
1950 & 3.284 & 14,33 \\
1955 & 2.368 & 10,33 \\
1960 & 1.990 & 8,68 \\
\hline Total & 22.916 & 100,00 \\
\hline
\end{tabular}

Fonte: Documento da Dataprev enviado ao autor. 


\subsection{Cálculo dos valores reais e das contribuições}

Uma vez montado o banco inicial e feitos os procedimentos descritos acima, a etapa seguinte consistiu no cálculo das contribuições previdenciárias feitas pelos segurados, pois no banco de dados original não há essa informação. É importante lembrar que os valores da remuneração Rem e do benefício RMI dos indivíduos estão expressos em múltiplos do salário mínimo nominal $\mathrm{SM}_{\text {nom }}$ vigente a cada mês, multiplicado por 100. Desta maneira, faz-se inicialmente o cálculo da Renda Nominal e do Benefício Nominal de cada segurado $i$ a cada mês $t$.

A seguir é feito o cálculo da contribuição previdenciária de cada trabalhador $i$ no mês $t$ de acordo com as alíquotas de contribuição incidentes sobre o empregado e sobre o empregador. Para que isso fosse possível, foi feita uma extensiva pesquisa na legislação previdenciária para encontrar todas as alíquotas vigentes de janeiro de 1980 a dezembro de 2006. Nestes 27 anos foram contadas 96 alterações de alíquotas, faixas ou limites de contribuição. A maior frequência de mudanças ocorre no período de maior turbulência inflacionária (e de planos econômicos) do país, entre 1986 e 1994.

Após o cálculo dos valores nominais das contribuições, foi feita a atualização dos valores para moeda constante de dezembro de 2006. Foi empregado nos cálculos o mesmo indicador empregado pelo MPS o Índice Nacional de Preços ao Consumidor (INPC). Para valores anteriores à mudança da moeda efetuada em julho de 1994, com o Plano Real, foi adotada a mesma metodologia que o Ipeadata utiliza para a série de salário mínimo nominal. A última etapa do procedimento empírico consistiu na imputação dos valores da $13^{\circ}$ parcela anual da renda e dos benefícios, com base no mês de dezembro de cada ano.

Duas hipóteses adotadas nos cálculos devem ser explicitadas. A primeira refere-se ao vínculo empregatício e à situação do contribuinte no mercado de trabalho. Empregados do setor privado de um lado, e trabalhadores por conta própria e empregados domésticos do outro, tradicionalmente vêm sendo tratados de forma diferente pela previdência social no Brasil, com regras contributivas diferenciadas. A alíquota dos conta-própria e dos domésticos sempre foi um pouco inferior a dos assalariados (considerando a soma das alíquotas do empregado e do empregador).

Na base de dados disponibilizada pela Dataprev, não é possível fazer a distinção entre empregados, trabalhadores por conta própria e empregados domésticos. Por este motivo, optou-se por considerar todos os indivíduos da amostra como empregados. Ao se adotar esta hipótese, o resultado é uma possível sobre-estimação das contribuições previdenciárias dos trabalhadores por conta própria e dos trabalhadores domésticos. Parece ser possível considerar que esta hipótese não é tão problemática. Dados do MPS mostram que em setembro de 2006 (data da coleta de dados da PNAD deste ano) havia no país 33,6 milhões de contribuintes. Destes, mais de $79 \%$ eram empregados. Ou seja, a possível sobre-estimação aplica-se a cerca de $21 \%$ da amostra. Deve ser ressaltado ainda que esta é uma informação do último ano (2006) da amostra. Para anos anteriores, a proporção de contribuintes que não eram empregados assalariados é certamente menor. Quanto mais próximos de 1980 forem os dados, menor será a imprecisão cometida com a hipótese feita.

\subsection{Imputação dos valores para períodos não observados}

Após o cômputo dos valores reais de todas as variáveis, procede-se à imputação dos dados para os períodos não observados, ou seja, os anos anteriores a 1982 e posteriores a 2006. Os dados iniciais contemplam um período de 25 anos (já contando o descarte dos dados de 1980 e 1981), relativamente reduzido frente ao ciclo de vida, que pode durar de 60 a 70 anos. Dado este fato, é necessário criar anos adicionais, referentes aos períodos pré-1982 e pós-2006, ao banco original. Posteriormente, nesses novos períodos são imputados os valores das variáveis monetárias (renda, contribuições e benefícios) e demais características observáveis. A estratégia adotada dividiu-se em duas partes. Para o período anterior a 1982 criou-se um banco de dados vazio, iniciado em 1944. A este banco foram incorporadas as informações invariáveis de cada indivíduo (identificador, Espécie de benefício, escolaridade). Posteriormente foram incorporadas as variáveis monetárias. As mais importantes são renda e as contribuições e, implicitamente, a densidade contributiva. Imputou-se a cada ano $t(t<1982)$ para cada indivíduo $i$ 
com um vetor de características $X$ os mesmos valores de renda e contribuições que os indivíduos com o mesmo vetor $X$ de características apresentam para os anos do intervalo 1982-2006. Considerando as variáveis disponíveis e as características fixas de cada indivíduo $i$ da mostra, definiu-se $X$ de acordo com a equação (4).

$$
X_{i}=X_{i} \text { (Idade,Sexo,Espécie de Benefício, Grupo Educacional). }
$$

Para a segunda parte, o período posterior a 2006, o procedimento é bem mais simples, tendo em vista que todos os trabalhadores já deverão ter obtido o benefício. Desta maneira, mimetizando o procedimento do MPS de manter constante o valor real dos benefícios, replicou-se para os anos posteriores a 2006 o último valor real efetivamente observado.

Um subproduto da manipulação dos dados deste trabalho é a obtenção da Densidade Contributiva (DC) para o período observado (1982-2006), conforme apresentado na equação (5). Este é um indicador da relação entre o número de contribuições previdenciárias efetivamente realizadas por cada indivíduo $i$ e o número máximo possível $N$ de contribuições que teriam sido realizadas caso o indivíduo permanecesse o tempo no mercado de trabalho formal ou não tivesse períodos de desemprego. Por construção, para cada segurado o valor de DC deve estar compreendido no intervalo $[0,1]$ :

$$
\mathrm{DC}_{i}=\frac{\sum_{t=1}^{N} \mathrm{~N}^{\circ} \text { Contrib }_{i t}}{N} .
$$

A incorporação da Densidade de Contribuições é uma diferença importante deste artigo em relação a trabalhos que empregam indivíduos representativos ou dados em cross-section, como a PNAD. Particularmente neste segundo caso, como não se tem as informações de toda vida ativa dos indivíduos, usualmente opta-se por considerar que o status contributivo foi o mesmo ao longo de toda a vida. Isto significa implicitamente a adoção de uma hipótese de densidade de contribuições igual a 1, o que certamente não ocorre, tendo em vista períodos de desemprego ou informalidade. $O$ valor de DC foi calculado para toda a amostra, no período para o qual estão disponíveis os valores primários de renda (1982-2006). Os dados mostraram que a densidade de contribuições é igual a 0,6975.

A última etapa consistiu na imputação da expectativa de sobrevida. Foram empregadas as tábuas de mortalidade por sexo abreviadas do Brasil, por coorte (com 5 anos) e por quinquênio, disponibilizadas pela Cepal ${ }^{3}$. Estas tábuas foram disponibilizadas para os quinquênios 1960-1965, 1955-1960 e 19501955. Como o banco apresenta indivíduos nascidos a partir de 1930, adotou-se um procedimento de extrapolação das expectativas de sobrevida para cada idade, para as coortes mais antigas. Na falta de informações mais precisas adotou-se uma forma de "agravar" as tábuas, com a consequente redução das expectativas de sobrevida. Isto foi feito adotando-se para cada grupo etário uma redução correspondente à média da razão encontrada para as tábuas para as quais se dispõe da informação. Exemplificando: suponha-se que de 1955-1960 para 1960-1965 a expectativa de vida para uma determinada idade passou de 18 para 20 anos; e que de 1950-1955 para 1955-1960 a expectativa de vida para uma determinada idade passou de 16 para 18 anos. Então o aumento médio foi a média entre 2/18 e 2/16.

\subsection{Cálculo dos Indicadores, exclusão de observações e identificação de outliers}

O primeiro indicador calculado, pela simplicidade operacional, foi a Taxa de Reposição TR. Seguindo o procedimento de vários autores, o cálculo foi feito, empregando não apenas a última remuneração imediatamente anterior à DIB, mas sim o período de 12 meses anterior à obtenção do benefício. 0 objetivo é tentar evitar que flutuações de curto prazo afetem os resultados.

Para um número elevado de beneficiários não foi possível efetuar o cálculo da TR, pois o período contributivo esgotava-se muito antes (mais de um ano) antes do início do recebimento da aposentadoria. Aparentemente esse é um puzzle inerente às características da base de dados, para o qual não foi

\footnotetext{
${ }^{3} \mathrm{O}$ autor agradece a Guiomar Bay pela disponibilização das tábuas.
} 
possível encontrar uma explicação consistente. Decidiu-se excluir da amostra todos os registros para os quais não foi possível calcular a TR. Com este procedimento, o número de indivíduos caiu de 7.325 para 1.733. Destes foram eliminadas 193 benefícios classificados como pensões, pelos motivos expostos anteriormente. Restaram, portanto apenas 1.540 observações. É inegável que esta é uma drástica redução.

Quando os indicadores TIR e AliqNec foram calculados, verificou-se a existência de alguns outliers, claramente incompatíveis com os padrões e resultados esperados para um sistema previdenciário. A identificação destes padrões está ligada aos valores reportados pela literatura empírica, apresentados por exemplo em Afonso \& Fernandes (2005), Giambiagi \& Afonso (2009), para o caso brasileiro, e Forteza \& Ourens (2009). Imagina-se que estes outliers possam ter origem em duas fontes. A primeira é algum tipo de problema nos registros administrativos da Dataprev. A segunda são distorções nos dados, em especial nos períodos de alta inflação e sucessivos planos econômicos, entre 1986 e 1994.

Optou-se pela realização de um procedimento de identificação e exclusão de outliers com base nos resultados calculados para TR, TIR e AliqNec. Seguindo a recomendação de Weber (2010) utilizou-se a rotina blocked adaptive computationally efficient outlier nominators (bacon $)^{4}$. 0 autor fornece evidências de que o seu emprego é vantajoso em relação à rotina hadimvo, apresentada por Hadi (1992) e Hadi (1994), visto que consegue identificar um conjunto similar de outliers, porém com ganhos computacionais. O emprego da rotina bacon implicou a eliminação de 95 dos 1.540 registros que compunham a amostra. É possível considerar como aceitável esta perda de cerca de $6,2 \%$, tendo em vista os objetivos do trabalho e o tipo de microdados utilizados. Os resultados reportados a seguir foram obtidos para os 1.445 registros restantes, que compõem o que se denominou por Amostra Completa.

\section{RESULTADOS}

Uma vez realizado o procedimento de construção do banco de dados, são apresentados os resultados dos Indicadores Previdenciários. Todos os valores são apresentados para a Amostra Completa e para as categorias de análise: sexo, Espécie de benefício, coorte, grupo educacional e quartil de renda. Antes, porém, são reportadas as estatísticas descritivas mais relevantes. A Tabela 4 apresenta o número de indivíduos da Amostra Completa, de acordo com o ano de nascimento e sexo. Os procedimentos de corte no banco explicam porque há apenas 14 indivíduos nascidos em 1960. Em 2006, ano mais recente da amostra, estes indivíduos tinham 46 anos, idade reduzida para a obtenção da ATC. Por outro lado, a

Tabela 4. Número de indivíduos por ano de nascimento e sexo.

\begin{tabular}{crcrrrrr}
\hline & \multicolumn{2}{c}{ Mulheres } & & \multicolumn{2}{c}{ Homens } & & Total \\
\cline { 2 - 3 } Ano & Número & $\%$ & & Número & $\%$ & & Número \\
\hline 1930 & 57 & 64,04 & & 32 & 35,96 & \\
1935 & 137 & 43,49 & & 178 & 56,51 & \\
1940 & 150 & 42,02 & & 207 & 57,98 & & 315 \\
1945 & 139 & 42,77 & & 186 & 57,23 & & 357 \\
1950 & 66 & 26,61 & & 182 & 72,39 & \\
1955 & 39 & 40,21 & & 58 & 59,79 & \\
1960 & 6 & 42,86 & & 8 & 57,14 & \\
\hline Total & 594 & 41,11 & & 851 & 58,89 & & 1.445 \\
\hline
\end{tabular}

Fonte: Elaboração do autor, com base nos registros administrativos da Dataprev.

${ }^{4}$ Esta rotina foi desenvolvida por Sylvain Weber e pode ser obtida em http://www. stata-journal.com/software/sj10-3. 
explicação para o baixo número de nascidos em 1930 (89 pessoas) é oposta. A expectativa de vida das coortes mais antigas é substancialmente menor do que a encontrada para as coortes mais novas.

Com exceção dos anos 1930 e 1950, a proporção de mulheres na amostra é relativamente estável As três coortes mais numerosas na amostra são as de 1940, 1945 e 1950, que representam mais de $64 \%$ do total. A Tabela 5 apresenta a tabulação cruzada entre as duas espécies de benefícios e sexo. Na amostra quase $62 \%$ dos benefícios são ATCs e o restante, AIs. Há uma diferenciação importante: os homens representam a maioria das ATCs $(78,7 \%)$ e as mulheres são o grupo majoritário $(62,12 \%)$ nas AIs. A predominância masculina já era esperada, tendo em vista que no passado a inserção da mulher no mercado de trabalho, particularmente no setor formal era bem menos expressiva. E posteriormente esta reduzida inserção reflete-se em um menor número de benefícios de aposentadoria programáveis.

Tabela 5. Número de beneficiários por Espécie de benefício e sexo.

\begin{tabular}{lcccccccc}
\hline & \multicolumn{2}{c}{ Mulheres } & & \multicolumn{2}{c}{ Homens } & & \multicolumn{2}{c}{ Total } \\
\cline { 2 - 3 } \cline { 7 - 8 } Espécie & Número & $\%$ & & Número & $\%$ & & Número & $\%$ \\
\hline AI (41) & 369 & 62,12 & & 181 & 37,88 & & 550 & 38,06 \\
ATC (42) & 225 & 21,27 & & 670 & 78,73 & & 895 & 61,94 \\
\hline Total & 594 & 41,11 & & 851 & 58,89 & & 1.445 & 100,00 \\
\hline
\end{tabular}

Fonte: Elaboração do autor, com base nos registros administrativos da Dataprev.

A Tabela 6 mostra que mais de $40 \%$ dos beneficiários da Amostra Completa fazia parte do Grupo Educacional 1. Nos grupos 2 e 3, que englobam indivíduos com maior escolaridade, o número de componentes é bem mais baixo. A única diferença digna de nota entre homens e mulheres refere-se à participação nos grupos 0 e 1 . Para quase um terço da amostra os microdados não apresentavam o nível educacional. Este problema é mais grave no caso feminino, em que quase $43 \%$ dos registros não apresentam essa informação. A informação sobre escolaridade é obtida quando da filiação ao RGPS, ou então em alguma situação que tenha justificado uma atualização das informações cadastrais. Como esta é uma informação acessória, não fundamental para o MPS, é provável que a confiabilidade destes dados não seja muito alta, tendo em vista que esforços adicionais de coleta teriam pouca valia. Esta hipótese é corroborada pela parcela, superior a $32 \%$, de pessoas para as quais não há dados para esta variável. De forma complementar, a Tabela 7 mostra que a qualidade das informações é melhor para as gerações mais novas, tendo em vista o menor número de beneficiários do Grupo 0.

Finalmente a Tabela 8 mostra outra importante diferença entre os sexos, no que se refere ao número de beneficiários por quartil de renda. A presença masculina (feminina) é muito mais expressiva nos quartis de renda mais altos (baixos), evidenciando que a remuneração dos homens é mais elevada que a das mulheres. Esta desigualdade se mostra bastante importante para explicar as diferenças encontradas para os indicadores previdenciários de ambos os sexos.

Tabela 6. Número de beneficiários por sexo e Grupo Educacional.

\begin{tabular}{|c|c|c|c|c|c|c|c|c|c|}
\hline \multirow[b]{2}{*}{ Sexo } & \multicolumn{2}{|c|}{ Grupo 0} & \multicolumn{2}{|c|}{ Grupo 1} & \multicolumn{2}{|c|}{ Grupo 2} & \multicolumn{2}{|c|}{ Grupo 3} & \multirow{2}{*}{$\frac{\text { Total }}{\text { Número }}$} \\
\hline & Número & $\%$ & Número & $\%$ & Número & $\%$ & Número & $\%$ & \\
\hline Mulheres & 254 & 42,76 & 190 & 31,99 & 103 & 17,34 & 47 & 7,91 & 594 \\
\hline Homens & 215 & 25,26 & 401 & 47,12 & 161 & 18,92 & 74 & 8,70 & 851 \\
\hline Total & 469 & 32,46 & 591 & 40,90 & 264 & 18,27 & 121 & 8,37 & 1.445 \\
\hline
\end{tabular}

Fonte: Elaboração do autor, com base nos registros administrativos da Dataprev. 
Tabela 7. Número de beneficiários por ano de nascimento e Grupo Educacional.

\begin{tabular}{|c|c|c|c|c|c|c|c|c|c|}
\hline \multirow[b]{2}{*}{ Ano } & \multicolumn{2}{|c|}{ Grupo 0} & \multicolumn{2}{|c|}{ Grupo 1} & \multicolumn{2}{|c|}{ Grupo 2} & \multicolumn{2}{|c|}{ Grupo 3} & \multirow{2}{*}{$\frac{\text { Total }}{\text { Número }}$} \\
\hline & Número & $\%$ & Número & $\%$ & Número & $\%$ & Número & $\%$ & \\
\hline 1930 & 72 & 80,90 & 16 & 17,98 & 1 & 1,12 & 0 & 0,00 & 89 \\
\hline 1935 & 176 & 55,87 & 101 & 32,06 & 24 & 7,62 & 14 & 4,44 & 315 \\
\hline 1940 & 121 & 33,89 & 157 & 43,98 & 58 & 16,25 & 21 & 5,88 & 357 \\
\hline 1945 & 70 & 21,54 & 161 & 49,54 & 63 & 19,38 & 31 & 9,54 & 325 \\
\hline 1950 & 24 & 9,68 & 115 & 46,37 & 76 & 30,65 & 33 & 13,31 & 248 \\
\hline 1955 & 6 & 6,19 & 34 & 35,05 & 37 & 38,14 & 20 & 20,62 & 97 \\
\hline 1960 & 0 & 0,00 & 7 & 50,00 & 5 & 35,71 & 2 & 14,29 & 14 \\
\hline Total & 469 & 32,46 & 591 & 40,90 & 264 & 18,27 & 121 & 8,37 & 1.445 \\
\hline
\end{tabular}

Fonte: Elaboração do autor, com base nos registros administrativos da Dataprev.

Tabela 8. Número de beneficiários por sexo e quartil de renda.

\begin{tabular}{|c|c|c|c|c|c|c|c|c|c|}
\hline \multirow[b]{2}{*}{ Sexo } & \multicolumn{2}{|c|}{ Quartil 1} & \multicolumn{2}{|c|}{ Quartil 2} & \multicolumn{2}{|c|}{ Quartil 3} & \multicolumn{2}{|c|}{ Quartil 4} & \multirow{2}{*}{$\frac{\text { Total }}{\text { Número }}$} \\
\hline & Número & $\%$ & Número & $\%$ & Número & $\%$ & Número & $\%$ & \\
\hline Mulheres & 232 & 39,06 & 183 & 30,81 & 99 & 16,67 & 80 & 13,47 & 594 \\
\hline Homens & 96 & 11,28 & 186 & 21,86 & 268 & 31,49 & 301 & 35,37 & 851 \\
\hline Total & 328 & 22,70 & 369 & 25,54 & 367 & 25,40 & 381 & 26,37 & 1.445 \\
\hline
\end{tabular}

Fonte: Elaboração do autor, com base nos registros administrativos da Dataprev.

As diferenças de remuneração também podem ser visualizadas por meio da evolução da renda do trabalho ao longo da vida ativa, seja para a Amostra Completa, seja para as categorias de análise previamente apresentadas. Devido ao tamanho reduzido da amostra (problema agravado quando as informações são segregadas por categorias), todos os gráficos são feitos por grupos etário de cinco anos.

A Figura 1 apresenta a renda média ao longo do ciclo de vida, para a Amostra Completa. Há nítida concavidade da curva, com o máximo situando-se antes dos 40 anos (o que é supreendentemente prematuro), decrescendo posteriormente e ficando praticamente estável a partir dos 55 a 59 anos. 0 formato da curva de renda deste gráfico pode ser mais bem compreendido por meio da comparação com a Figura 2, que traz a renda média por Grupo Educacional. Como era esperado, o Grupo 3 (educação superior) tem um prêmio salarial substantivo em relação aos Grupos 2 (ensino médio) e 1 (ensino fundamental). É razoável inferir que o formato ascendente da curva da Figura 1 para as idades mais baixas é parcialmente explicado pelo comportamento da renda do grupo de maior escolaridade (embora possa se notar que a renda dos demais grupos também tenha concavidade, não tão facilmente visível por causa da escala do gráfico), conforme pode ser visto na Figura 2. 0 trecho ascendente para as idades mais elevadas não parece ter efeito global significativo, dado o reduzido número de indivíduos que faz parte deste grupo. Desta forma, o efeito dos Grupos 1 e 2 tem certa sobreposição. 0 comportamento do Grupo 0 (para o qual não se tem informações sobre educação) é bastante similar ao verificado para os Grupos 1 e 2, o que leva a crer que a não-informação do nível educacional é mais expressiva para as duas faixas educacionais inferiores. O perfil de renda é relativamente diferente daquele apresentado por Giambiagi \& Afonso (2009, p.162-164), o que é um sinal de que o uso de dados em cross-section como a PNAD pode gerar certas discrepâncias frente ao uso de registros administrativos aqui adotados.

A Figura 3 traz a renda média por idade desagregada por sexo. Para a maioria das idades a renda masculina é mais elevada, o que deve estar ligado às diferenças de escolaridade. Na Figura 4 é mostrada 
Figura 1. Renda mensal real (R\$ de dez./2006) por Grupo etário - Amostra Completa.

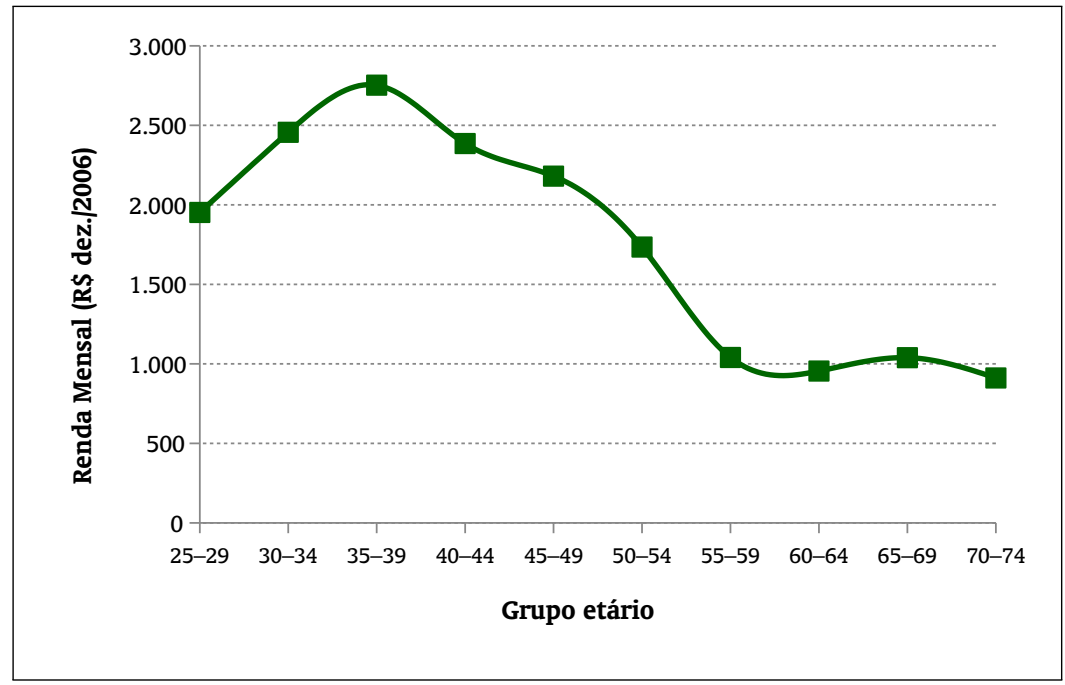

Fonte: Elaboração do autor, com base nos registros administrativos da Dataprev.

Figura 2. Renda mensal real (R\$ de dez./2006) por Grupo etário e Grupo Educacional.

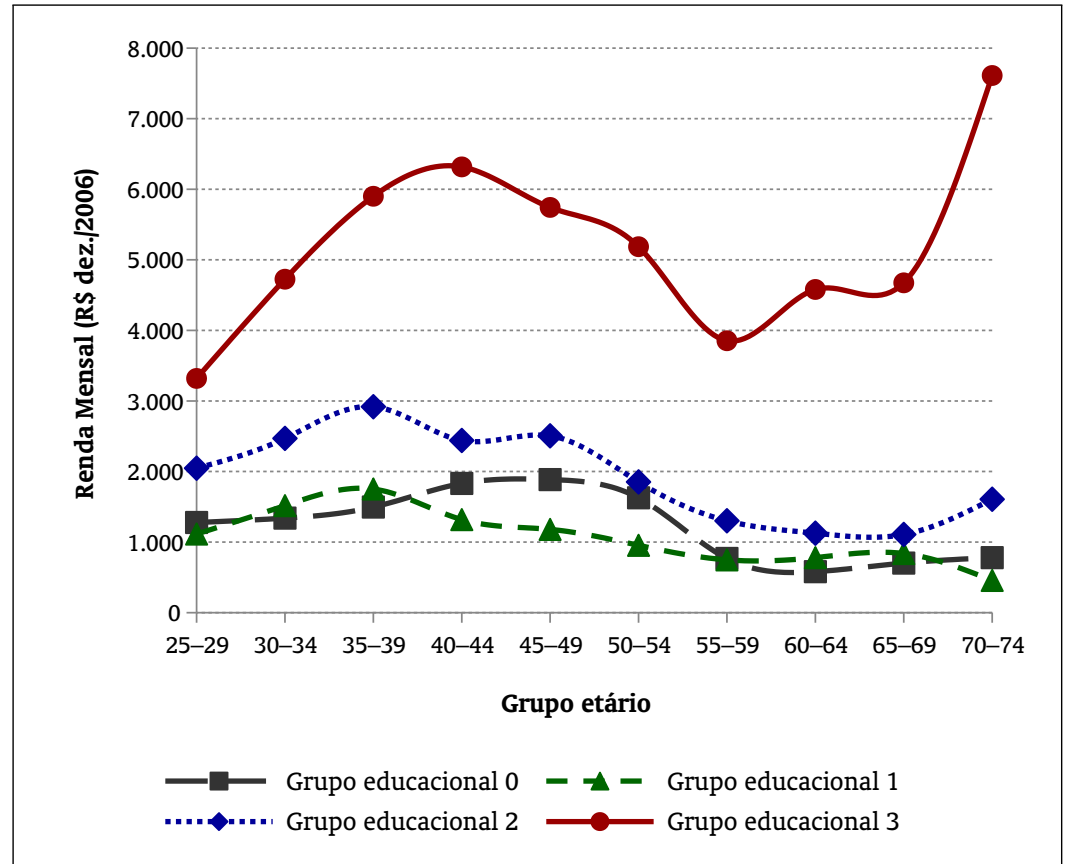

Fonte: Elaboração do autor, com base nos registros administrativos da Dataprev. 
Figura 3. Renda mensal real (R\$ de dez./2006) por Grupo etário e sexo.

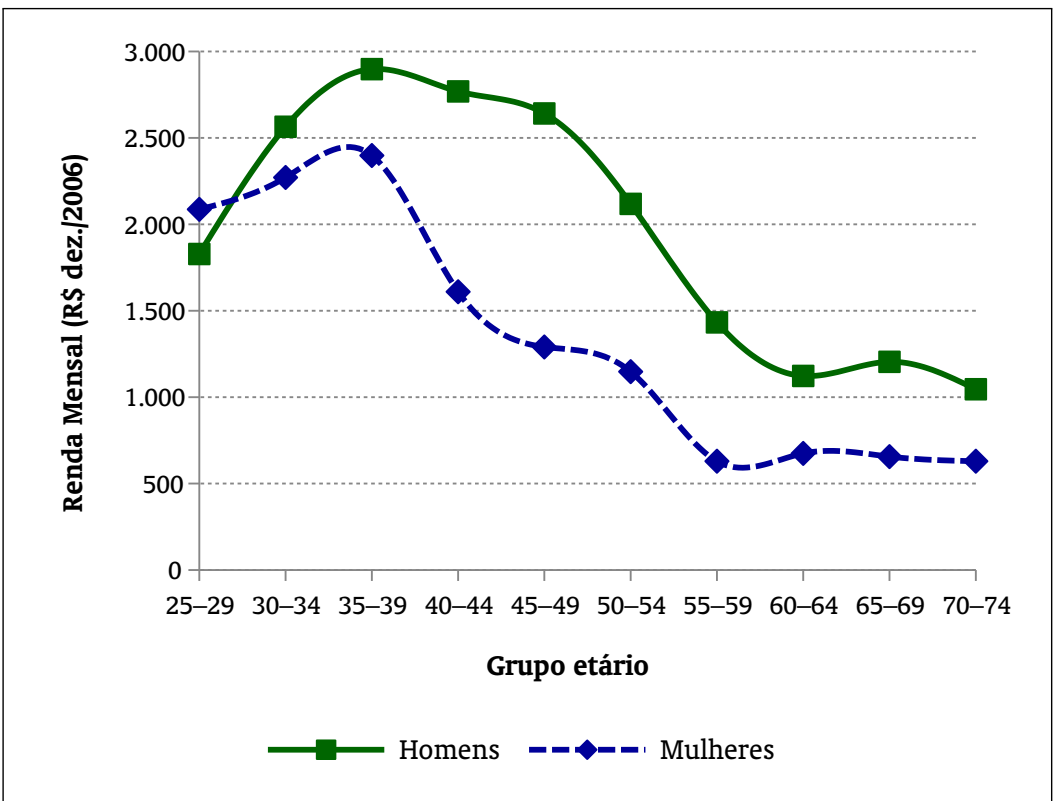

Fonte: Elaboração do autor, com base nos registros administrativos da Dataprev.

Figura 4. Renda mensal real (R\$ de dez./2006) por Grupo etário e Espécie de benefício.

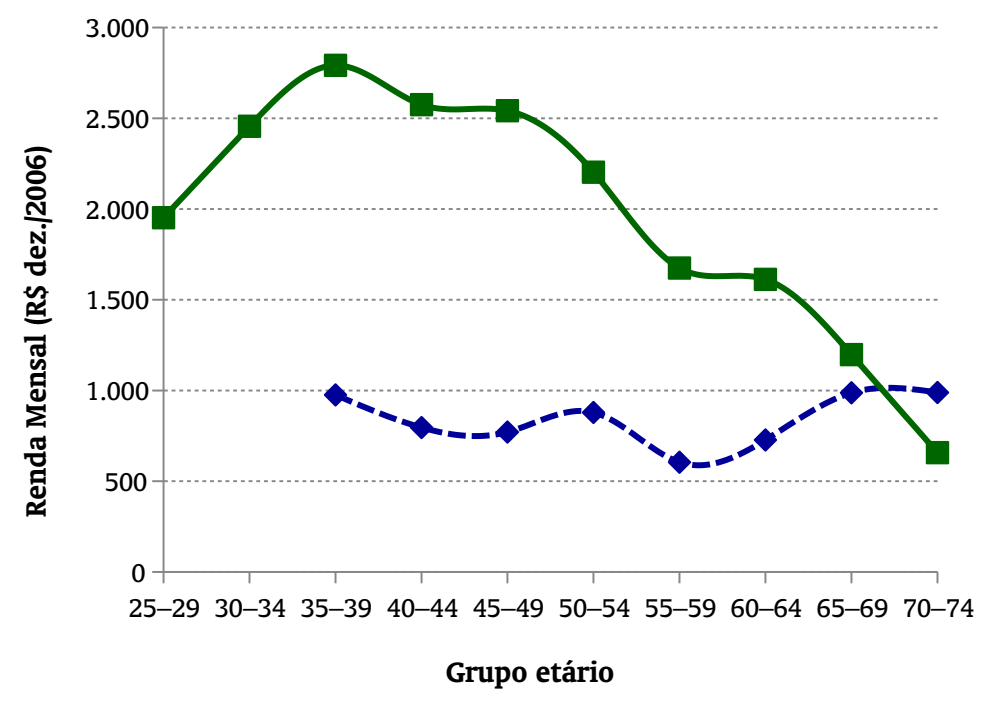

- - $\bullet-\boldsymbol{-}$. Aposentadoria por Idade

$\longrightarrow$ Aposentadoria por Tempo de Contribuição

Fonte: Elaboração do autor, com base nos registros administrativos da Dataprev. 
a renda dos indivíduos que se aposentaram por tempo de contribuição e dos que obtiveram o benefício por idade. Há evidentes diferenças, com maiores ganhos para o primeiro grupo. Este resultado está em consonância com fatos estilizados da previdência social no Brasil, em que indivíduos que obtêm a ATC têm renda mais elevada e se aposentam mais cedo, além de terem valor de benefício mais elevado. Este argumento pode ser visualizado na Tabela 9, na qual são reportados os valores médios da renda e dos benefícios, por quartil de renda e para a Amostra Completa. Também é apresentada a relação entre benefícios e renda, que decresce monotonicamente com o aumento da renda. Este indicador fornece mais uma evidência de que o RGPS, para os benefícios em análise, apresenta progressividade. Análise similar pode ser feita com base na Tabela 10, na qual os valores são segregados pela Espécie de benefício.

Tabela 9. Valor médio dos benefícios e da renda por Quartil de renda (Valores em R\$ de dezembro de 2006).

\begin{tabular}{lccccc}
\hline & Quartil 1 & Quartil 2 & Quartil 3 & Quartil 4 & Amostra Completa \\
\hline Benefício médio & 382,67 & 745,51 & $1.309,16$ & $2.054,92$ & $1.151,55$ \\
Renda média & 288,61 & 580,31 & $1.207,60$ & $4.533,21$ & $1.715,67$ \\
Benefício/Renda (\%) & 132,59 & 128,47 & 108,41 & 45,33 & 67,12 \\
\hline Número & 328 & 369 & 367 & 381 & 1.445 \\
\hline
\end{tabular}

Fonte: Elaboração do autor, com base nos registros administrativos da Dataprev.

Tabela 10. Valor médio dos beneficios e da renda por Espécie de benefício (Valores em R\$ de dezembro de 2006).

\begin{tabular}{lccc}
\hline & AI & ATC & Amostra Completa \\
\hline Benefício médio & 640,99 & $1.465,31$ & $1.151,55$ \\
Renda média & 697,31 & $2.341,47$ & $1.715,67$ \\
Benefício/Renda (\%) & 91,92 & 62,58 & 67,12 \\
\hline Número & 550 & 895 & 1.445 \\
\hline
\end{tabular}

Fonte: Elaboração do autor, com base nos registros administrativos da Dataprev.

\subsection{Taxa de Reposição (TR)}

Nesta seção são apresentados os resultados obtidos para a Taxa de Reposição TR. São reportados os valores para a Amostra Completa e por categoria de análise. A TR média para os 1.445 indivíduos da Amostra Completa foi de elevados 82,52\%. A Tabela 11 reporta esses valores. Parece haver evidências de redução da TR ao longo do tempo para as coortes mais novas. Esta diminuição pode ser entendida como uma evidência da existência de um windfall associado à expansão do sistema previdenciário no Brasil. Este fato é similar ao verificado por Leimer $(2004,2007)$ e Duggan et al. (1993) para os EUA.

A Tabela 12 apresenta os valores desagregados por sexo. A TR feminina é cerca de 10 pontos percentuais superior à masculina. Talvez esta diferença esteja associada às características da remuneração média dos segurados e à existência de um teto para o valor dos benefícios. Esta linha de raciocínio é corroborada pelos resultados da Tabela 13, que mostra que as TRs das AIs são mais de 20 pontos percentuais mais elevadas que as das ATCs. Os resultados da Tabela 14 mostram que com exceção do Grupo 0 os valores são tão mais elevados quanto menor é o nível educacional. Os valores da TR são reportados para os quartis de renda na Tabela 15. Quanto maior a renda, mais baixa é a TR.

Este primeiro conjunto de resultados deve ser analisado em conjunto. Chama a atenção o elevado valor médio encontrado comparativamente a outros trabalhos. Estes valores são bem mais altos que 
Tabela 11. Taxa de Reposição (TR) por coorte.

\begin{tabular}{lrccrc}
\hline Coorte & $N$ & Média (\%) & Desvio-padrão & Mínimo & Máximo \\
\hline 1930 & 89 & 95,14 & 32,74 & 10,42 & 230,16 \\
1935 & 315 & 86,37 & 36,20 & 7,16 & 246,17 \\
1940 & 357 & 87,71 & 33,68 & 6,25 & 241,16 \\
1945 & 325 & 84,23 & 36,53 & 5,86 & 266,96 \\
1950 & 248 & 73,35 & 37,13 & 8,64 & 261,07 \\
1955 & 97 & 60,45 & 30,11 & 10,98 & 165,60 \\
1960 & 14 & 58,71 & 26,08 & 24,51 & 105,62 \\
\hline Amostra Completa & 1.445 & 82,52 & 36,12 & 5,86 & 266,96 \\
\hline
\end{tabular}

Fonte: Elaboração do autor, com base nos registros administrativos da Dataprev.

Tabela 12. Taxa de Reposição (TR) por sexo.

\begin{tabular}{lrcccc}
\hline Sexo & $N$ & Média (\%) & Desvio-padrão & Mínimo & Máximo \\
\hline Feminino & 594 & 88,32 & 32,54 & 5,86 & 246,17 \\
Masculino & 851 & 78,46 & 37,92 & 6,18 & 266,96 \\
\hline Amostra Completa & 1.445 & 82,52 & 36,12 & 5,86 & 266,96 \\
\hline
\end{tabular}

Fonte: Elaboração do autor, com base nos registros administrativos da Dataprev.

Tabela 13. Taxa de Reposição (TR) por Espécie de benefício.

\begin{tabular}{lrcccc}
\hline Espécie de benefício & \multicolumn{1}{c}{$N$} & Média (\%) & Desvio-padrão & Mínimo & Máximo \\
\hline AI (41) & 550 & 96,27 & 30,04 & 7,16 & 241,16 \\
ATC (42) & 895 & 74,07 & 36,95 & 5,86 & 266,96 \\
\hline Amostra Completa & 1.445 & 82,52 & 36,12 & 5,86 & 266,96 \\
\hline
\end{tabular}

Fonte: Elaboração do autor, com base nos registros administrativos da Dataprev.

Tabela 14. Taxa de Reposição (TR) por Grupo Educacional.

\begin{tabular}{lcccrc}
\hline Grupo Educacional & $N$ & Média (\%) & Desvio-padrão & Mínimo & Máximo \\
\hline Grupo Educacional 0 & 469 & 86,63 & 33,63 & 5,86 & 231,41 \\
Grupo Educacional 1 & 591 & 89,55 & 35,03 & 12,40 & 266,96 \\
Grupo Educacional 2 & 264 & 75,57 & 34,47 & 6,18 & 196,64 \\
Grupo Educacional 3 & 121 & 47,39 & 31,49 & 8,64 & 166,98 \\
\hline Amostra Completa & 1.445 & 82,52 & 36,12 & 5,86 & 266,96 \\
\hline
\end{tabular}

Fonte: Elaboração do autor, com base nos registros administrativos da Dataprev. 
Tabela 15. Taxa de Reposição (TR) por quartil de renda.

\begin{tabular}{lrccrc}
\hline Quartil de renda & $N$ & Média (\%) & Desvio-padrão & Mínimo & Máximo \\
\hline Quartil 1 & 328 & 101,42 & 27,81 & 17,72 & 246,17 \\
Quartil 2 & 369 & 89,94 & 33,96 & 7,16 & 241,16 \\
Quartil 3 & 367 & 86,54 & 32,19 & 12,40 & 266,96 \\
Quartil 4 & 381 & 55,18 & 32,41 & 5,86 & 243,26 \\
\hline Amostra Completa & 1.445 & 82,52 & 36,12 & 5,86 & 266,96 \\
\hline
\end{tabular}

Fonte: Elaboração do autor, com base nos registros administrativos da Dataprev.

aqueles reportados por Giambiagi \& Afonso (2009) e Penafieri \& Afonso (2013).

Estas diferenças podem ser um sinal de que o RGPS é generoso, comparativamente aos regimes previdenciários de outros países. Evidencia-se que as primeiras gerações foram beneficiadas. Em outras palavras, estes resultados fornecem um subsídio à tese da existência de transferências intergeracionais e principalmente da existência de um windfall no RGPS, nos moldes apontados por Feldstein \& Liebman (2002) e Feldstein (2005a, 2005b). O segundo aspecto refere-se à existência de transferências intrageracionais. Foram encontrados valores diferentes de TR para grupos separados por critérios distintos, como gênero, Espécie de benefício, nível educacional e renda. Valores mais altos foram obtidos para as AIs, frente à ATCs, para as mulheres em relação aos homens, para os indivíduos menos educados em relação aos de maior escolaridade e para os primeiros quartis de renda, comparativamente aos últimos quartis. Quanto menor a renda do segurado, mais elevada será sua TR.

\subsection{Taxa Interna de Retorno (TIR)}

O segundo Indicador Previdenciário é a Taxa Interna de retorno (TIR). O valor médio real obtido foi de 5,32\% ao ano para a Amostra Completa, o que também está bastante acima dos padrões encontrados na literatura. Os dados por coorte evidenciam um expressivo aumento dos valores para as coortes mais novas (Tabela 16), de forma distinta do que foi verificado para a TR, em que os valores mais elevados foram encontrados para as coortes mais antigas. Um padrão similar de resultados havia sido encontrado por Afonso \& Fernandes (2005), porém sem a desagregação entre trabalhadores dos setores privado e público. Os valores médios aqui encontrados $(5,32 \%)$ são inferiores àqueles verificados no trabalho citado (6,7\%). Porém são bem mais elevados, em média, que os valores calculados por Caetano (2006) e Penafieri \& Afonso (2013). De forma similar ao verificado para a TR, a TIR média dos homens é sensivelmente mais baixa que a das mulheres. Este fato pode ser verificado na Tabela 17.

Os resultados separados por Grupo Educacional, reportados na Tabela 18, parecem apontar que os segurados de escolaridade baixa têm TIR bem mais elevada que os de escolaridade média ou superior. Na sequência (Tabela 19), a desagregação por Espécie de benefício mostra que as TIRs calculadas para as AIs são cerca de 4 pontos percentuais mais altas do que aquelas verificadas para as ATCs. Os dados por quartil de renda (Tabela 20) apresentam o mesmo padrão: maiores valores estão associados aos grupos de renda mais baixa, com bastante similaridade entre o segundo e o terceiro quartis, mas com notável diferença entre os extremos da distribuição. Estes elevados resultados reforçam as evidências de progressividade do RGPS.

\subsection{Alíquota Necessária (AliqNec)}

A Alíquota Necessária representa a alíquota que deveria incidir sobre a renda do segurado para que o valor presente das suas contribuições fosse igual ao valor presente dos benefícios. Os valores encontrados são bastante elevados. O valor médio ultrapassa $50 \%$. O valor de AliqNec cresce a partir da coorte de 1930, até atingir o máximo para a coorte de 1940, em que o valor máximo ultrapassa os 55\%. Para as 
Tabela 16. Taxa Interna de Retorno (TIR) por coorte.

\begin{tabular}{lrccrc}
\hline Coorte & $N$ & Média (\% a.a.) & Desvio-padrão & Mínimo & Máximo \\
\hline 1930 & 89 & 4,34 & 2,67 & $-3,12$ & 14,76 \\
1935 & 315 & 4,75 & 3,84 & $-10,56$ & 21,08 \\
1940 & 357 & 5,90 & 4,95 & $-3,90$ & 21,75 \\
1945 & 325 & 5,53 & 4,77 & $-1,84$ & 25,97 \\
1950 & 248 & 4,82 & 3,28 & $-3,99$ & 22,27 \\
1955 & 97 & 6,22 & 3,53 & $-0,90$ & 15,74 \\
1960 & 14 & 7,70 & 4,83 & 1,72 & 16,94 \\
\hline Amostra Completa & 1.445 & 5,32 & 4,25 & $-10,56$ & 25,97 \\
\hline
\end{tabular}

Fonte: Elaboração do autor, com base nos registros administrativos da Dataprev.

Tabela 17. Taxa Interna de Retorno (TIR) por sexo.

\begin{tabular}{lcccrc}
\hline Sexo & $N$ & Média (\% a.a.) & Desvio-padrão & Mínimo & Máximo \\
\hline Feminino & 594 & 6,33 & 4,64 & $-10,56$ & 25,97 \\
Masculino & 851 & 4,62 & 3,79 & $-4,09$ & 21,54 \\
\hline Amostra Completa & 1.445 & 5,32 & 4,25 & $-10,56$ & 25,97 \\
\hline
\end{tabular}

Fonte: Elaboração do autor, com base nos registros administrativos da Dataprev.

Tabela 18. Taxa Interna de Retorno (TIR) por Grupo Educacional.

\begin{tabular}{lcccrc}
\hline Grupo Educacional & $N$ & Média (\% a.a.) & Desvio-padrão & Mínimo & Máximo \\
\hline Grupo Educacional 0 & 469 & 6,54 & 4,72 & $-10,56$ & 25,97 \\
Grupo Educacional 1 & 591 & 5,65 & 3,89 & $-2,68$ & 22,10 \\
Grupo Educacional 2 & 264 & 3,95 & 3,46 & $-3,99$ & 21,54 \\
Grupo Educacional 3 & 121 & 2,01 & 2,82 & $-4,09$ & 17,27 \\
\hline Amostra Completa & 1.445 & 5,32 & 4,25 & $-10,56$ & 25,97 \\
\hline
\end{tabular}

Fonte: Elaboração do autor, com base nos registros administrativos da Dataprev.

Tabela 19. Taxa Interna de Retorno (TIR) por Espécie de beneficio.

\begin{tabular}{lrccrc}
\hline Espécie de benefício & $N$ & Média (\% a.a.) & Desvio-padrão & Mínimo & Máximo \\
\hline AI (41) & 550 & 7,86 & 4,47 & $-10,56$ & 25,97 \\
ATC (42) & 895 & 3,77 & 3,24 & $-4,09$ & 22,27 \\
\hline Amostra Completa & 1.445 & 5,32 & 4,25 & $-10,56$ & 25,97 \\
\hline
\end{tabular}

Fonte: Elaboração do autor, com base nos registros administrativos da Dataprev. 
Tabela 20. Taxa Interna de Retorno (TIR) por quartil de renda.

\begin{tabular}{lcccrc}
\hline Quartil de renda & $N$ & Média (\% a.a.) & Desvio-padrão & Mínimo & Máximo \\
\hline Quartil 1 & 328 & 6,66 & 5,04 & $-3,12$ & 22,10 \\
Quartil 2 & 369 & 5,59 & 4,20 & $-4,09$ & 20,51 \\
Quartil 3 & 367 & 5,39 & 4,07 & $-3,99$ & 25,97 \\
Quartil 4 & 381 & 3,85 & 3,13 & $-10,56$ & 18,40 \\
\hline Amostra Completa & 1.445 & 5,32 & 4,25 & $-10,56$ & 25,97 \\
\hline
\end{tabular}

Fonte: Elaboração do autor, com base nos registros administrativos da Dataprev.

gerações seguintes foram encontrados valores mais reduzidos, chegado até os $43 \%$ da geração de 1960 (ver Tabela 21). A Tabela 22 mostra que a alíquota feminina deveria ser próxima a 58\% para prover equilíbrio entre contribuições e benefícios, valor mais de 12 pontos percentuais superior àquele encontrado para os homens. Da mesma forma verificada para a TIR (e de forma oposta à verificada para a TR), os valores decrescem monotonicamente para os níveis educacionais mais elevados. Há grande diferença entre os valores dos Grupos de educação 1 e 3 (Tabela 23). Para as Espécies de benefícios, verifica-se comportamento similar, com valores bem mais elevados para as AIs comparativamente às ATCs (Tabela 24). Finalmente, quando a dimensão de análise é a renda, os valores mais elevados (quase 53\%) são encontrados para indivíduos de renda mais baixa (Tabela 25). À medida que a renda aumenta, o valor da alíquota diminui, até chegar ao valor médio de pouco mais de $40 \%$ para o quartil de renda mais elevada.

Os resultados encontrados para as Alíquotas Necessárias merecem alguma reflexão. Um primeiro ponto refere-se à comparação dos valores calculados, em relação aos demais indicadores. Pode-se afirmar que estes valores são bastante consistentes, se analisados à luz dos demais resultados deste trabalho. Valores mais elevados para TIR, AliqNec e TR estão associados à níveis de renda mais baixos, à aposentadoria por idade, às mulheres e aos grupos com menor nível educacional. Como subsídio adicional ao argumento pró-progressividade, apresenta-se a Tabela 26, na qual é feita uma tabulação cruzada entre os valores da TIR e da TR, por quartil. Há clara correlação entre estes dois indicadores: valores mais elevados para a TIR correspondem a valores maiores para a TR e vice-versa.

\subsection{Qual a taxa de desconto adequada para um regime de repartição? A proposta do uso da TIR}

É possível argumentar que a taxa de juros de mercado pode não ser a escolha mais adequada para um regime de repartição, tendo-se em vista a inexistência de ativos neste tipo de regime. Tal escolha eventualmente poderia ser defensável se considerarmos a ótica (ou as finanças) da entidade previdenciária. Suponha-se que por qualquer motivo, as contribuições associadas a um regime de repartição sejam eliminadas. É o caso, por exemplo, de uma mudança imediata para um regime de capitalização. Com a eliminação do fluxo de receitas contributivas, o ente previdenciário deve buscar uma alternativa, tendo em vista que é necessário fazer o phasing-out dos benefícios do regime de repartição.

Eliminando-se a possibilidade de emissão de moeda, a única possibilidade restante é a emissão de títulos, com aumento da dívida pública e o pagamento de juros aos compradores dos títulos. Desta forma, o custo de oportunidade para o governo, associado à eliminação das contribuições, está ligado à taxa de juros de longo prazo dos títulos públicos. Para entender o problema de outra forma vale voltar ao conceito de Contribution Asset, explorado no texto de Boado-Penas et al. (2008, p.92-93), juntamente com o Actuarial Balance Sheet do regime previdenciário. A abordagem dos autores é engenhosa, visto que conseguem reunir em um mesmo trabalho princípios econômicos associados ao regime de repartição e princípios atuariais (a preocupação com a solvência intertemporal da entidade previdenciária). Neste caso, calcular os ativos do sistema significa, de forma tautológica, calcular o valor do passivo previdenciário. 
Tabela 21. Alíquota Necessária (AliqNec) por coorte.

\begin{tabular}{lrccrr}
\hline coorte & $N$ & Média (\%) & Desvio-padrão & Mínimo & Máximo \\
\hline 1930 & 89 & 49,69 & 27,72 & 3,20 & 136,42 \\
1935 & 315 & 52,98 & 32,66 & 1,65 & 184,32 \\
1940 & 357 & 55,87 & 35,84 & 4,87 & 198,75 \\
1945 & 325 & 48,68 & 28,66 & 5,40 & 166,35 \\
1950 & 248 & 45,52 & 27,61 & 7,07 & 204,77 \\
1955 & 97 & 43,73 & 23,23 & 9,16 & 124,92 \\
1960 & 14 & 43,16 & 26,24 & 15,67 & 96,49 \\
\hline Amostra Completa & 1.445 & 50,53 & 31,13 & 1,65 & 204,77 \\
\hline
\end{tabular}

Fonte: Elaboração do autor, com base nos registros administrativos da Dataprev.

Tabela 22. Alíquota Necessária (AliqNec) por sexo.

\begin{tabular}{lrcccc}
\hline Sexo & $N$ & Média (\%) & Desvio-padrão & Mínimo & Máximo \\
\hline Feminino & 594 & 57,59 & 33,68 & 1,65 & 204,77 \\
Masculino & 851 & 45,60 & 28,21 & 3,20 & 198,75 \\
\hline Amostra Completa & 1.445 & 50,53 & 31,13 & 1,65 & 204,77 \\
\hline
\end{tabular}

Fonte: Elaboração do autor, com base nos registros administrativos da Dataprev.

Tabela 23. Alíquota Necessária (AliqNec) por Grupo Educacional.

\begin{tabular}{lccccc}
\hline Grupo Educacional & $N$ & Média (\%) & Desvio-padrão & Mínimo & Máximo \\
\hline Grupo Educacional 0 & 469 & 60,37 & 33,98 & 1,65 & 204,77 \\
Grupo Educacional 1 & 591 & 53,95 & 28,79 & 5,45 & 177,61 \\
Grupo Educacional 2 & 264 & 38,20 & 24,97 & 4,87 & 198,75 \\
Grupo Educacional 3 & 121 & 22,53 & 12,49 & 3,51 & 102,92 \\
\hline Amostra Completa & 1.445 & 50,53 & 31,13 & 1,65 & 204,77 \\
\hline
\end{tabular}

Fonte: Elaboração do autor, com base nos registros administrativos da Dataprev.

Tabela 24. Alíquota Necessária (AliqNec) por Espécie de benefício.

\begin{tabular}{lrcccc}
\hline Espécie de benefício & \multicolumn{1}{c}{$N$} & Média (\%) & Desvio-padrão & Mínimo & Máximo \\
\hline AI (41) & 550 & 69,72 & 31,93 & 1,65 & 198,75 \\
ATC (42) & 895 & 38,74 & 23,95 & 3,51 & 204,77 \\
\hline Amostra Completa & 1.445 & 50,53 & 31,13 & 1,65 & 204,77 \\
\hline
\end{tabular}

Fonte: Elaboração do autor, com base nos registros administrativos da Dataprev. 
Tabela 25. Alíquota Necessária (AliqNec) por quartil de renda.

\begin{tabular}{lccccc}
\hline Quartil de renda & $N$ & Média (\%) & Desvio-padrão & Mínimo & Máximo \\
\hline Quartil 1 & 328 & 52,89 & 26,55 & 4,86 & 128,35 \\
Quartil 2 & 369 & 55,13 & 35,72 & 3,51 & 168,95 \\
Quartil 3 & 367 & 54,67 & 34,11 & 4,87 & 204,77 \\
Quartil 4 & 381 & 40,05 & 23,84 & 1,65 & 184,32 \\
\hline Amostra Completa & 1.445 & 50,53 & 31,13 & 1,65 & 204,77 \\
\hline
\end{tabular}

Fonte: Elaboração do autor, com base nos registros administrativos da Dataprev.

Tabela 26. Observações por quartil de TIR e quartil de TR.

\begin{tabular}{|c|c|c|c|c|c|c|c|c|c|}
\hline \multirow[t]{2}{*}{ Quartil } & \multicolumn{2}{|c|}{1} & \multicolumn{2}{|c|}{2} & \multicolumn{2}{|c|}{3} & \multicolumn{2}{|c|}{4} & \multirow{2}{*}{$\frac{\text { Total }}{\text { Número }}$} \\
\hline & Número & $\%$ & Número & $\%$ & Número & $\%$ & Número & $\%$ & \\
\hline 1 & 131 & 34,20 & 98 & 25,59 & 81 & 21,15 & 73 & 19,06 & 383 \\
\hline 2 & 109 & 28,84 & 94 & 24,87 & 91 & 24,07 & 84 & 22,22 & 378 \\
\hline 3 & 93 & 24,73 & 101 & 26,86 & 93 & 24,73 & 89 & 23,67 & 376 \\
\hline 4 & 41 & 13,31 & 81 & 26,30 & 92 & 29,87 & 94 & 30,52 & 308 \\
\hline Total & 374 & 25,88 & 374 & 25,88 & 357 & 24,71 & 340 & 23,53 & 1.445 \\
\hline
\end{tabular}

Fonte: Elaboração do autor, com base nos registros administrativos da Dataprev.

Nesta seção propõe-se o uso da TIR para descontar os valores monetários em um regime de repartição. Esta escolha pode ser mais bem compreendida deslocando-se o foco da entidade previdenciária para o beneficiário. Um regime previdenciário é um tipo de contrato social envolvendo o governo e os trabalhadores. $O$ recebimento do benefício está condicionado à realização de contribuições. Em outras palavras, o trabalhador aceita uma redução em sua renda líquida presente para que possa obter renda futura. A relação entre os fluxos de contribuições e de benefícios define a TIR associada à sua participação no sistema previdenciário. Ou, expressando de outra forma, o custo de oportunidade para o trabalhador, associado a não contribuir à previdência, corresponde a não obter a TIR.

Com base neste argumento, nesta seção o cálculo da Alíquota Necessário é refeito, desta vez empregando como taxa de desconto o valor da TIR individual, calculado previamente para cada beneficiário da amostra. O emprego de um valor de TIR para cada indivíduo é justificado pelo fato desta, conforme apontado anteriormente, refletir o custo de oportunidade de cada segurado. De certa forma, é como se fosse empregado como taxa de desconto o valor da biological interest rate inerente a um regime de repartição, apresentada pela primeira vez no clássico trabalho de Samuelson (1958), porém com agentes heterogêneos e com a generalização apresentada por Settergren \& Mikula (2005, p.124). A heterogeneidade fundamenta-se nos valores diferentes obtidos para os Indicadores Previdenciários, particularmente a TIR, calculados para as categorias de análise aqui empregadas. Já a dedução apresentada por esta dupla, mostra que a TIR pode ser expressa como a soma de três termos:

(i) Mudanças nas contribuições, ligadas às alterações no nível de renda, na participação na PEA e nas alíquotas de contribuição;

(ii) Mudanças no turnover duration ${ }^{5}$, ligadas a alterações na estrutura demográfica;

(iii) Juros (recebidos ou pagos) sobre os ativos (positivos ou negativos) do sistema.

\footnotetext{
${ }^{5}$ O turnover duration pode ser entendido de forma simplificada como a diferença das idades médias dos ativos e dos inativos do sistema.
} 
$\mathrm{O}$ valor médio de AliqNec é bem mais próximo para a média dos indivíduos. Também se nota expressiva redução na dispersão dos valores calculados, pois o coeficiente de variação reduz-se de cerca de 0,62 para 0,44. Quando os resultados por categorias são analisados notam-se expressivas diferenças em relação aos valores originais de AliqNec, calculados com o emprego de uma taxa de desconto de 3\% ao ano. Para as gerações mais novas, o valor torna-se pouco superior a 20\% (Tabela 27). Outro exemplo ocorre com a alíquota por gênero. No cálculo inicial, o valor médio de AliqNec para mulheres (homens) era de $57,59 \%$ (45,60\%). Empregando-se a TIR, os valores alteram-se, respectivamente, para $26,67 \%$ e 30,36 (Tabela 28). Ou seja, a Alíquota Necessária para as mulheres agora é inferior à masculina. A explicação é que inicialmente os benefícios de ambos os sexos foram trazidos a valor presente à mesma taxa, $3 \%$. Com a TIR média, a taxa empregada para os homens aumenta para $4,62 \%$; já para as mulheres o aumento é ainda maior, pois a TIR média é de 6,33. Este aumento afeta mais os benefícios do que as contribuições, tendo em vista que as aposentadorias encontram-se mais distantes no tempo, o que reduz mais fortemente seu valor presente. De todas as categorias analisadas, a que apresenta a mudança de resultados mais radical é a Espécie de benefício. O novo valor médio de AliqNec para as ATCs $(31,61 \%)$ é sensivelmente menor que o valor para as AIs (24,34\%). Novamente a explicação é que no caso das AIs, o aumento na taxa de desconto é bem mais drástico do que para as ATCs.

Tabela 27. Alíquota Necessária (AliqNec) com o uso da TIR por coorte.

\begin{tabular}{lrccrr}
\hline Coorte & $N$ & Média (\%) & Desvio-padrão & Mínimo & Máximo \\
\hline 1930 & 89 & 30,67 & 12,09 & 3,45 & 78,24 \\
1935 & 315 & 32,42 & 16,25 & 1,01 & 188,50 \\
1940 & 357 & 29,20 & 14,71 & 0,99 & 100,28 \\
1945 & 325 & 29,03 & 9,70 & 3,36 & 65,57 \\
1950 & 248 & 26,19 & 7,78 & 2,11 & 92,55 \\
1955 & 97 & 21,70 & 4,37 & 1,37 & 30,88 \\
1960 & 14 & 20,19 & 2,95 & 16,09 & 25,50 \\
\hline Amostra Completa & 1.445 & 28,85 & 12,68 & 0,99 & 188,50 \\
\hline
\end{tabular}

Fonte: Elaboração do autor, com base nos registros administrativos da Dataprev.

Tabela 28. Alíquota Necessária (AliqNec) com o uso da TIR por sexo.

\begin{tabular}{lccccc}
\hline Sexo & $N$ & Média (\%) & Desvio-padrão & Mínimo & Máximo \\
\hline Feminino & 594 & 26,67 & 14,08 & 0,99 & 188,5 \\
Masculino & 851 & 30,36 & 11,37 & 1,01 & 92,55 \\
\hline Amostra Completa & 1.445 & 28,85 & 12,68 & 0,99 & 188,5 \\
\hline
\end{tabular}

Fonte: Elaboração do autor, com base nos registros administrativos da Dataprev.

\section{CONCLUSÕES}

Os resultados obtidos fornecem evidências significativas de progressividade no RGPS, para os beneficios de ATC e AI. Esta progressividade é resultado de terem sido encontrados valores mais elevados dos indicadores TR, TIR e AliqNec para as gerações mais antigas, mulheres, beneficiários com menor escolaridade e renda mais baixa. Os resultados são consistentes entre si. Este estudo corrobora para o Brasil os resultados encontrados por outros pesquisadores para vários países, com especial destaque para os EUA. No entanto, com exceção da TR, não há sinais tão claros da existência de windfall no RGPS. Também 
Tabela 29. Alíquota Necessária (AliqNec) com o uso da TIR por Grupo Educacional.

\begin{tabular}{lccccr}
\hline Grupo Educacional & \multicolumn{1}{c}{$N$} & Média (\%) & Desvio-padrão & Mínimo & Máximo \\
\hline Grupo Educacional 0 & 469 & 26,25 & 14,33 & 0,99 & 188,50 \\
Grupo Educacional 1 & 591 & 29,01 & 10,91 & 1,20 & 89,88 \\
Grupo Educacional 2 & 264 & 31,63 & 12,07 & 1,37 & 100,28 \\
Grupo Educacional 3 & 121 & 32,01 & 13,28 & 8,71 & 76,40 \\
\hline Amostra Completa & 1.445 & 28,85 & 12,68 & 0,99 & 188,50 \\
\hline
\end{tabular}

Fonte: Elaboração do autor, com base nos registros administrativos da Dataprev.

Tabela 30. Alíquota Necessária (AliqNec) com o uso da TIR por Espécie de benefício.

\begin{tabular}{lrcccc}
\hline Espécie de benefício & \multicolumn{1}{c}{$N$} & Média (\%) & Desvio-padrão & Mínimo & Máximo \\
\hline AI (41) & 550 & 24,34 & 13,42 & 0,99 & 188,50 \\
ATC (42) & 895 & 31,61 & 11,36 & 1,37 & 100,28 \\
\hline Amostra Completa & 1.445 & 28,85 & 12,68 & 0,99 & 188,50 \\
\hline
\end{tabular}

Fonte: Elaboração do autor, com base nos registros administrativos da Dataprev.

Tabela 31. Alíquota Necessária (AliqNec) com o uso da TIR por quartil de renda.

\begin{tabular}{lccccr}
\hline Quartil de renda & $N$ & Média (\%) & Desvio-padrão & Mínimo & Máximo \\
\hline Quartil 1 & 328 & 25,48 & 13,66 & 0,99 & 78,24 \\
Quartil 2 & 369 & 28,48 & 12,14 & 2,23 & 76,40 \\
Quartil 3 & 367 & 30,04 & 11,86 & 1,01 & 100,28 \\
Quartil 4 & 381 & 30,95 & 12,52 & 2,11 & 188,50 \\
\hline Amostra Completa & 1.445 & 28,85 & 12,68 & 0,99 & 188,50 \\
\hline
\end{tabular}

Fonte: Elaboração do autor, com base nos registros administrativos da Dataprev.

se pode considerar como um achado a variabilidade verificada para estes indicadores. Aparentemente, há grande heterogeneidade no RGPS que não vinha sendo captada de forma adequada em trabalhos anteriores.

O valor médio encontrado para a TR é de elevados $82,5 \%$, bem acima da média internacional. Para todas as categorias de análise foram encontrados princípios de progressividade. Os valores encontrados também são bem mais altos do que os encontrados por outros autores, como Giambiagi \& Afonso (2009) e Penafieri \& Afonso (2013). Esta parece ser uma diferença relevante dos achados deste trabalho em relação a trabalhos que empregaram grupos de indivíduos representativos. Conclusões similares são obtidas com base nos resultados da TIR. Porém para este indicador, o valor médio de 5,32\% a.a. não é tão mais elevado do que outros estudos encontraram.

O valor médio obtido para AliqNec, superior a 50\%, é bastante elevado frente a outras evidências reportadas na literatura. Embora também tenham sido obtidas evidências de progressividade para este indicador, elas parecem ser menos significativas do que as verificadas com a TR e a TIR. Por exemplo, a diferença entre os quartis de renda é de apenas 12 pontos percentuais. Há valores muito altos, que talvez esteja associada a densidades contributivas baixas, o que faz com que o período contributivo efetivo seja baixo frente do período de recebimento do benefício. É possível que estes valores sejam resultado da arbitragem racional que os contribuintes faziam frente a regras de cálculo do valor do benefício e 
condições de elegibilidade pouco rigorosas de. Não se pode descartar que, particularmente em épocas mais distantes, tenha havido maior subdeclaração de renda (e contribuições) com relação aos períodos que não faziam parte do cálculo do valor da aposentadoria, o que impactou positivamente AliqNec.

Com base nestes resultados foi feito um exercício adicional, relacionado a uma corrente da literatura cujo foco é a análise da solvência e das medidas de riqueza associadas aos sistemas previdenciários. Parte desta literatura advoga, fundamentada no conceito de Contribution Asset (Boado-Penas et al., 2008), que a taxa de desconto empregada para regimes de repartição não deve ser a taxa de juros de ativos sem risco. 0 correto seria empregar como taxa de desconto o retorno obtido pelos contribuintes por fazerem parte de um regime de repartição (Settergren \& Mikula, 2005). Os valores de AliqNec foram recalculados, empregando para cada indivíduo os valores de suas TIRs individuais previamente calculados.

Esta mudança altera bastante os resultados. Para as mulheres, beneficiários da AI, com menor nível de escolaridade e dos primeiros quartis de renda, os valores de AliqNec são bem menores. Isso ocorre principalmente porque os benefícios são descontados com o emprego de taxas bem mais elevadas do que havia sido feito inicialmente. Para os grupos do extremo oposto da distribuição, ocorre fenômeno inverso. A interpretação dos resultados não é imediata. Pode ser entendido que ela é uma medida mais adequada, do ponto de vista individual da existência dos aspectos distributivos, tendo em vista a heterogeneidade verificada nos resultados das seções anteriores.

Quando analisados em conjunto os resultados deste artigo permitem aprofundar o conhecimento sobre aspectos do sistema previdenciário no Brasil, com foco nos dois benefícios programáveis mais importantes do RGPS. Ao contrário do que o senso comum usualmente costuma advogar, tais benefícios não são nem um pouco reduzidos, quando comparados às contribuições correspondentes, por meio dos indicadores calculados. Deve ser citada também o cálculo da densidade contributiva, da ordem de 70\%. Esta informação não pode ser obtida com o emprego de dados em cross-section ou de indivíduos representativos, como tem sido feito no Brasil. De um lado, a forte evidência de progressividade captada pelos indicadores é um retrato da generosidade das regras previdenciárias. De outro, a reduzida densidade contributiva é outra evidência de que o ônus do financiamento dos benefícios recai sobre parcela reduzida dos trabalhadores. Em conjunto, tais características são o reflexo de um desenho inadequado do RGPS, tendo como resultados déficits de grande magnitude, que oneram a sociedade, impõem custos elevados e prejudicam a adequada alocação de recursos públicos.

Tendo em vista os resultados e os pontos levantados, pode-se considerar que este trabalho fez uma contribuição original à literatura brasileira sobre previdência. Evidências significativas de progressividade no RGPS, para as aposentadorias por tempo de contribuição e por idade são o achado mais relevante. De forma complementar, imagina-se que trabalhos posteriores possam seguir metodologia similar e investigar os benefícios de risco, até o momento pouco abordados no Brasil.

\section{REFERÊNCIAS BIBLIOGRÁFICAS}

Aaron, H. (1966). The social insurance paradox. The Canadian Journal of Economics and Political Science/Revue canadienne d'Economique et de Science politique, 32(3), 371-374. Disponível em: http://www.jstor.org/ stable/139995

Afonso, L. E., \& Fernandes, R. (2005). Uma estimativa dos aspectos distributivos da previdência social no Brasil. Revista Brasileira de Economia, 59(3), 295-334. Disponível em: http://bibliotecadigital.fgv.br/ojs/index .php/rbe/article/view/971

Aldrich, J. (1982). The earnings replacement rate of old-age benefits in 12 countries, 1969-80. Social Security Bulletin, 45(11), 3-11. Disponível em: https://www.socialsecurity.gov/policy/docs/ssb/v45n11/v45n11p3.pdf

Alonso, J., Hoyo, C. \& Tuesta, D. (2015). A model for the pension system in Mexico: Diagnosis and recommendations. Journal of Pension Economics and Finance, 14(1), 76-112. doi: 10.1017/S147474721400016X

Barr, N., \& Diamond, P. (2006). The economics of pensions. Oxford Review of Economic Policy, 22(1), 15-39 . doi: $10.1093 / 0 x r e p / g r j 002$

Barr, N., \& Diamond, P. (2008). Reforming pensions: Principles and policy choices. Oxford: Oxford Univ. Press. 
Barr, N., \& Diamond, P. (2009). Reforming pensions: Principles, analytical errors and policy directions. International Social Security Review, 62(2), 5-29. doi: 10.1111/j.1468-246X.2009.01327.x

Bertranou, F. M., \& Sánchez, A. P. (2003). Características y determinantes de la densidad de aportes a la Seguridad Social en la Argentina 1994-2001. In F. M. Bertrano, M. Bourquín \& H. Pena (Eds.), Historias laborales en la Seguridad Social (pp. 37-64). Buenos Aires: Ministerio de Trabajo, Empleo y Seguridad Social. Disponível em: http://www.ilo.org/buenosaires/publicaciones/WCMS_BAI_PUB_101/lang--es/index.htm

Biggs, A. G., Sarney, M. \& Tamborini, C. R. (2009, January). A progressivity index for social security (Issue Paper $\mathrm{N}^{0}$ 2009-01). Washington, DC: Social Security Administration (SSA). Disponível em: https://www.ssa.gov/ policy/docs/issuepapers/ip2009-01.html

Boado-Penas, M. d. C., Valdés-Prieto, S. \& Vidal-Meliá, C. (2008). The actuarial balance sheet for pay-as-you-go finance: Solvency indicators for Spain and Sweden. Fiscal Studies, 29(1), 89-134. doi: 10.1111/j.14755890.2008.00070.x

Brown, R. L. (1998). Social security: Regressive or progressive? North American Actuarial Journal, 2(2), 1-23. doi: 10.1080/10920277.1998.10595687

Brown, R. L., \& Ip, J. (2000). Social security: Adequacy, equity, and progressiveness. North American Actuarial Journal, 4(1), 1-17. doi: 10.1080/10920277.2000.10595866

Bucheli, M., Forteza, A. \& Rossi, I. (2010). Work histories and the access to contributory pensions: The case of Uruguay. Journal of Pension Economics and Finance, 9(3), 369-391. doi: 10.1017/S1474747208003776

Caetano, M. A.-R. (2006, agosto). Subsídios cruzados na previdência social brasileira (Texto para Discussão No 1211). Brasília, DF: Instituto de Pesquisa Econômica Aplicada - IPEA. Disponível em: http://repositorio.ipea .gov.br/handle/11058/2183\#

Duggan, J. E., Gillingham, R. \& Greenlees, J. S. (1993). Returns paid to early social security cohorts. Contemporary Economic Policy, 11(4), 1-13. doi: 10.1111/j.1465-7287.1993.tb00396.x

Duggan, J.E., Gillingham, R. \& Greenlees, J.S. (1995). Progressive returns to social security? An answer from social security records (Research Paper $\mathrm{N}^{0}$ 9501). Washington DC: Treasury Department. Disponível em: http://www.treasury.gov/resource-center/economic-policy/Documents/rp9501.pdf

Feldstein, M. (2005a). Rethinking social insurance. American Economic Review, 95(1), 1-24. doi: $10.1257 / 0002828053828545$

Feldstein, M. (2005b). Structural reform of social security. Journal of Economic Perspectives, 19(2), 33-55. doi: $10.1257 / 0895330054048731$

Feldstein, M., \& Liebman, J. B. (2002). Social security. In M. Feldstein \& A. J. Auerbach (Eds.), Handbook of public economics (Vol. 4, pp. 2245-2324). Amsterdam: North-Holland.

Fernandes, F. (1994). Sistema previdenciário e desigualdades inter e intrageracionais no Brasil: 0 papel da dinâmica demográfica. Previdência em Dados, 9(4), 5-36.

Forteza, A., Apella, I., Fajnzylber, E., Grushka, C., Rossi, I. \& Sanroman, G. (2009, December). Work histories and pension entitlements in Argentina, Chile and Uruguay (SP Discussion Paper $\mathrm{N}^{0}$ 0926). Washington, DC: World Bank. Disponível em: http://documents.worldbank.org/curated/en/2009/12/11587564/work-histories -pension-entitlements-argentina-chile-uruguay

Forteza, A., \& Ourens, G. (2009, August). How much do Latin American pension programs promise to pay back? (Social Protection Discussion Paper $\mathrm{N}^{0}$ 0927). Washington, DC: World Bank. Disponível em: http://documents .worldbank.org/curated/en/2009/12/11587833/much-latin-american-pension-programs-promise-pay-back

Forteza, A., \& Ourens, G. (2012). Redistribution, insurance and incentives to work in Latin-American pension programs. Journal of Pension Economics and Finance, 11(3), 337-364. doi: 10.1017/S1474747211000564

Garrett, D. M. (1995). The effects of differential mortality rates on the progressivity of social security. Economic Inquiry, 33(3), 457-475. doi: 10.1111/j.1465-7295.1995.tb01874.x

Giambiagi, F., \& Afonso, L. E. (2009). Cálculo da alíquota de contribuição previdenciária atuarialmente equilibrada: Uma aplicação ao caso brasileiro. Revista Brasileira de Economia, 63(2), 153-179. Disponível em: http:// bibliotecadigital.fgv.br/ojs/index.php/rbe/article/view/1207

Gragnolati, M., Jorgensen, O. H., Rocha, R. \& Fruttero, A. (2011). Growing old in an older Brazil : Implications of population ageing on growth, poverty, public finance, and service delivery (Directions in Development / 
Human Development). Washington DC: World Bank. Disponível em: https://openknowledge.worldbank.org/ handle/10986/2351

Haanes-Olsen, L. (1978). Earnings-replacement rate of old-age benefits, 1965-75, selected countries. Social Security Bulletin, 41(1), 3-14. Disponível em: http://www.ssa.gov/policy/docs/ssb/v41n1/v41n1p3.pdf

Hadi, A. S. (1992). Identifying multiple outliers in multivariate data. Journal of the Royal Statistical Society. Series B (Methodological), 54(3), 761-771. Disponível em: http://www.jstor.org/stable/2345856

Hadi, A. S. (1994). A modification of a method for the detection of outliers in multivariate samples. Journal of the Royal Statistical Society. Series B (Methodological), 56(2), 393-396. Disponível em: http://www.jstor.org/ stable/2345910

Horlick, M. (1970). The earnings replacement rate of old-age benefits: An international comparison. Social Security Bulletin, 33(3), 3-16. Disponível em: http://www.ssa.gov/policy/docs/ssb/v33n3/v33n3p3.pdf

Hurd, M. D., \& Shoven, J.B. (1985). The distributional impact of social security [National Bureau of Economic Research Project Report]. In D. A. Wise (Ed.), Pensions, labor, and individual choice (pp. 193-222). Boston, MA: University of Chicago Press. Disponível em: http://www.nber.org/chapters/c7134

Leimer, D. R. (1999, April). Lifetime redistribution under the Social Security Program: A literature synopsis (ORES Working Paper Series $\mathrm{N}^{0}$ 81). Washington, DC: Social Security Administration (SSA). Disponível em: https://ssa.gov/policy/docs/workingpapers/wp81.pdf

Leimer, D. R. (2004, February). Historical redistribution under the Social Security Old-Age and Survivors Insurance and Disability Insurance programs (ORES Working Paper $\mathrm{N}^{0}$ 102). Washington, DC: Social Security Administration (SSA). Disponível em: https://www.ssa.gov/policy/docs/workingpapers/wp102.html

Leimer, D. R. (2007, December). Cohort-specific measures of lifetime social security taxes and benefits (ORES Working Paper $\mathrm{N}^{0} 110$ ). Washington, DC: Social Security Administration (SSA). Disponível em: https:// www.ssa.gov/policy/docs/workingpapers/wp110.html

Moura, R. L. d., Jesus Filho, J.d., Tafner, P. S. B. \& Ourives, L. H.d.C. (2013). Social security effects on income distribution: A counterfactual analysis for Brazil. Applied Economics Letters, 20(7), 631-637. doi: $10.1080 / 13504851.2012 .725922$

Musgrave, R. (1985). A brief history of fiscal doctrine. In M. Feldstein \& A. J. Auerbach (Eds.), Handbook of public economics (Vol. 1, pp. 1-59). Amsterdam: North-Holland. doi: 10.1016/S1573-4420(85)80004-5

Pallares-Miralles, M., Romero, C. \& Whitehouse, E. (2012, June). International patterns of pension provision II: A worldwide overview of facts and figures (Social Protection \& Labor Discussion Paper $\mathrm{N}^{0}$ 1211). Washington, DC: The World Bank. Disponível em: https://openknowledge.worldbank.org/bitstream/handle/10986/13560/ 703190NWPOSPL000Box370035B00PUBLIC0.pdf

Penafieri, A. C., \& Afonso, L. E. (2013). O impacto da mudança da regra de cálculo das aposentadorias por tempo de contribuição do INSS: 0 Fator Previdenciário é atuarialmente justo? Economia Aplicada, 17(4), 667-694. doi: 10.1590/S1413-80502013000400007

Reis, C. d. B., \& Turra, C. M. (2011, dezembro). Desigualdade regional na distribuição dos recursos previdenciários: Uma análise das transferências intrageracionais e de período. In $39^{\circ}$ Encontro Nacional de Economia da ANPEC, Foz do Iguaçu - PR. Disponível em: http://anpec.org.br/encontro/2011/inscricao/arquivos/000 -014c04d01c28b616ad0a50a96758a87b.pdf

Reznik, G. L., Weaver, D. A. \& Biggs, A. G. (2009, April). Social security and marginal returns to work near retirement (Issue Paper $\mathrm{N}^{0}$ 2009-02). Washington, DC: Social Security Administration (SSA). Disponível em: https://www.ssa.gov/policy/docs/issuepapers/ip2009-02.html

Samuelson, P. A. (1958). An exact consumption-loan model of interest with or without the social contrivance of money. Journal of Political Economy, 66(6), 467-482. Disponivel em: http://www.jstor.org/stable/1826989

Schröder, C. (2012). Profitability of pension contributions: Evidence from real-life employment biographies. Journal of Pension Economics and Finance, 11(3), 311-336. doi: 10.1017/S147474721100031X

Settergren, O., \& Mikula, B. D. (2005). The rate of return of pay-as-you-go pension systems: a more exact consumption-loan model of interest. Journal of Pension Economics and Finance, 4(2), 115-138. doi: $10.1017 / S 1474747205002064$ 
Shoven, J. B., \& Slavov, S. N. (2012a, February). The decision to delay social security benefits: Theory and evidence (Working Paper $\mathrm{N}^{0}$ 17866). National Bureau of Economic Research. doi: 10.3386/w17866

Shoven, J. B., \& Slavov, S. N. (2012b, July). When does it pay to delay social security? The impact of mortality, interest rates, and program rules (Working Paper $\mathrm{N}^{0}$ 18210). National Bureau of Economic Research. doi: $10.3386 /$ w18210

Shoven, J. B., \& Slavov, S. N. (2014). Does it pay to delay social security? Journal of Pension Economics and Finance, 13(2), 121-144. doi: 10.1017/S1474747213000309

Weber, S. (2010). bacon: An effective way to detect outliers in multivariate data using Stata (and Mata). Stata Journal, 10(3), 331-338. doi: http://www.stata-journal.com/article.html?article=st0197 